\title{
A General Theory of Autoimmune Disease Causation: Integrating Innate and Adaptive Immunity, Altered Antigen Processing, Sex and Genetic Predispositions, and Microbiome Effects.
}

\author{
Robert Root-Bernstein, Ph. D., Department of Physiology, 567 Wilson Road, Room 2201, Michigan State \\ University, East Lansing, MI 48824 USA; rootbern@msu.edu
}

\begin{abstract}
Current theories of autoimmunity are diverse, sometimes contradictory, and suffer from incompleteness. Although substantial evidence exists that adaptive and innate immunity, sex, genetic predisposition, and the microbiome all play essential roles in autoimmune disease etiologies and pathogenesis, and that antigen processing is altered during disease induction, no existing theory integrates all of these factors through a single, coherent mechanism. In an attempt to focus the field on the need to elucidate such an integrative mechanism, I propose one possibility here that, if nothing else, helps to identify the nature of the problems that need to be addressed. My theory is that autoimmune diseases are induced by normal immunological responses to unique pairs of complementary antigens, at least one of which is a molecular mimic of a host target. Each antigen in the complementary pair induces a complementary immune response ( $T$ or $B$ cell); although each immune response is idiotypic in origin, the antigenic complementarity results in what appears to be an idiotype-anti-idiotype relationship between the responses. Additionally, because of the antigenic complementarity, each immune response mimics one of antigens, abrogating the distinction between self and non-self. If at least one of the antigens mimics a host antigen, then the resulting immunological civil war spreads to a host tissue. Complementary antigens also alter antigen processing so that antigens that would normally be proteolytically digested are presented by the major histocompatibility complex (MHC) to T and B cell receptors inducing a cross-reactive immune response. The resulting civil war is supported by the innate immune system due to the complementarity of the initiating antigens.. Complementary antigens stimulate synergistic toll-like receptors (TLR) and/or nucleotide-binding oligomerization receptors (NOD) resulting in up-regulation of cytokine production and further stimulation of the adaptive immune response. Because the immune responses (e.g., antibodies) mimic the initiating antigens, this synergistic activation of innate immunity becomes chronic. Additionally, TLR and NOD function are highly sensitive to sex hormones, some becoming up-regulated and some down-regulated in the presence of either testosterone or estrogens. This sensitivity explains how sex modifies susceptibility to autoimmune diseases. Genetic mutations in TLR, NOD and MHC further alter antigen presentation and the degree to which antigens stimulate an immune response explaining how genetics also modifies susceptibility. Finally, sex hormones also alter the host microbiome, which in turn modulates autoimmune disease risk by shaping the immunological nature of self and by mediating susceptibility to microbial infection. Moreover, it appears that the microbiome camouflages itself from the immune system by mimicking the host antigenic repertoire; the mimicry between the antigens of the microbiome and the host results in selective attacks on microbiome constituents concomitant with any autoimmune attack on host tissues. This antigenic complementarity theory thereby integrates all major elements known to affect, or be affected by, autoimmune diseases and provides a set of testable implications.
\end{abstract}


Keywords: autoimmunity; toll-like receptors; TLR; nucleotide-binding oligomerization domain; NOD1; major histocompatibility complex; MHC; human leukocyte antigens; HLA; proteasome; innate immunity; adaptive immunity; T cells; B cells; antibodies; microbiome; tolerance; self; non-self; antigen processing

\section{Introduction}

Theories play multiple roles in science. One is to integrate disparate observations within an internally coherent explanation that is consistent with already accepted scientific principles. A second is to use incomplete data to generate novel predictions about phenomena that may be overlooked within current research paradigms. A third purpose is to examine, and even to challenge, the assumptions underlying existing explanations of phenomena to make them explicitly amenable to testing. A fourth purpose is to address unresolved problems, anomalies, and contradictions within existing explanatory frameworks (Kuhn, 1959). These four roles - explanation, challenge, prediction and anomaly-accounting - provide tests for the relative merits of competing theories. The value of a theory is not only in whether there are data to support it, but whether it leaves significant anomalies or bodies of data unexplained, and what testable predictions it makes that other theories do not (Root-Bernstein, 1989). Finally, as one of my mentors in college, Art Pardee, maintained, "It is more important that a theory be interesting than that it be correct." Incorrect theories can still be very "interesting" if they lead us to perform experiments we would otherwise not consider and yield unexpected phenomena we would otherwise not explore. Many important discoveries have resulted from disproving "interesting" theories (RootBernstein, 1989). It is in this light that I proffer the following theory of the role of infections as triggers of autoimmune diseases.

My goal is to integrate a broad set of phenomena that have been experimentally characterized but not yet explained coherently and integrally within any existing theory of autoimmune disease (AD). As anyone who has studied AD knows, there are at least a dozen competing theories currently circulating and there is evidence to support each. However, as Fairweather and I have recently demonstrated with regard to autoimmune myocarditis, every type of evidence favoring one theory can be explained by at least one other theory and no existing theory explains all of the available evidence (Root-Bernstein and Fairweather, 2015). Strikingly, no existing theory integrally accounts for why the disease agents associated with most $A D$ are very common, yet particular $A D$ are usually quite rare; how some of these disease agents can be associated with the induction of more than one AD; provides a mechanism by which most, but not all, $A D$ susceptibility is skewed towards women; incorporates a role for innate immunity in supporting $A D$ pathogenesis; provides a mechanism for the formation of circulating immune complexes (CIC) and perivascular cuffs in AD; explains why so-called "adjuvants" are required to induce $A D$ in virtually all animal models of disease; or provides mechanisms by which $A D$ can influence the host microbiome and vice-versa. These outstanding problems represent the kinds of anomalous findings that Kuhn (1959) would argue calls for "paradigm shift" in explaining AD. I propose a theory that explains these currently disparate phenomena within a single explanatory framework. 
Among the assumptions that I have adopted in devising this new theory is one very fundamental one, which is that autoimmunity is not a mistake or error. I reject out of hand AD theories such as the escaped clone, aberrant signaling, T-cell-B-cell discordance, and dendritic malfunction theories because they rely on chance mistakes or errors. From a purely theoretical perspective, chance or random error is not experimentally testable and useless in furthering research or making clinically relevant progress. Additionally, from an experimental perspective, chance or random error cannot explain the facility with which virtually every animal in a test group can be given an $A D$ under controlled conditions. Thus, I have assumed instead that $A D$ result from the immune system properly doing the job it evolved to do, but under conditions that result in unusual and unexpected consequences. In short, I argue that autoimmunity is a normal response to rare circumstances rather than that $A D$ result from aberrations in immune function.

\section{Background: What Function Did the Immune System Evolve to Serve?}

Before it is possible to understand how autoimmune diseases disrupt normal organismal functioning, it is necessary to understand the molecular bases governing this functioning and what roles the immune system plays within this context. Particularly important are two principles that dominate molecular interactions both within and between hosts and their microbial communities: molecular complementarity and molecular mimicry.

All living systems are characterized by being built from a limited set of highly interactive components sometimes described as an "interactome". Molecules aggregate into highly ordered, functional units at varying levels of complexity ranging from macromolecular complexes and organelles to cells, from cells to tissues and organs, and finally to the organism itself. The organizing principle at every level of organization is molecular complementarity - the intrinsic property of some molecules to take on structures and bonding patterns that permit them to interact reversibly with a select group of other molecules, macromolecules, or supra-molecular aggregates or cells (Root-Bernstein and Dillon, 1997; Hunding, et al., 2006; Norris and Root-Bernstein, 2009). Living organisms are, in short, comprised of highly-integrated, molecularly-complementary networks (Root-Bernstein, 2012; Csermely, 2006).

Molecular complementarity also determines and regulates microbial infectivity (Pizarro-Cerdá and Cossart, 2006; Ribeta and Cossart, 2015). The mechanistic basis upon which any two organisms form a commensal, symbiotic, parasitic or pathogenic relationship is the ability of the molecular mechanisms of each organism to mesh functionally with the other. Molecules produced by a microbe must be functional in the context of its host's interactome. The identification of host cells by microbes generally relies on molecular complementarity between specific proteins on the cell surface of the microbe and receptors or transporters on the cell surface of host cells (e.g., Rosenshine \& Finley, 1993; Cossart \& Sansonetti, 2004; Thorley, et al., 2010; Kalia \& Jameel, 2011). Since host molecules already interact functionally with these receptors or transporters, there is a reasonable likelihood that the microbial molecules that interact with the receptors or transporters will mimic the host ligands. Indeed, it has recently been "discovered" that many commensal microbes produce mimics of receptor ligands (Cohen, et al., 2017), although it has been known since the 1980s that the cell-wall breakdown product muramyl dipeptide mimics both the binding activity and some of the functions of serotonin (Root-Bernstein \& 
Westall, 1990; Takeuchi, et al., 1990; Krueger, et al., 1984). Thus, through evolutionary processes of variation and selection, molecular complementarity can lead to molecular mimicry of microbes for their hosts.

Mimicry of microbial molecules for host molecules has important immunological consequences. Damian (Damian, 1965; Damian, 1967; Damian, 1989) was the first to argue that parasites evolved to use such mimicry to hide from the immune system of the host. The more the parasitic molecules "look" like host molecules, the less likely the host immune system is able to recognize them as antigens. Subsequent studies have expanded Damian's concept to viruses, bacteria and other microbes (Fujinami, et al., 1983; Davies, 1997; Rose, 2017). All commensal and symbiotic microbes display significant antigen similarity to their hosts, while pathogens exhibit lower levels of mimicry (He, et al., 2015; RootBernstein, 2016).

One role of the immune system is to prevent microbial interference with the host microbiome by regulating, obviating or eliminating infections. Because microbes are constantly evolving to avoid immune detection by selection to mimic host antigens, the immune system has evolved to make ever finer distinctions between "self" and "non-self". Highly auto-reactive lymphocyte clones are eliminated during development, as are completely non-reactive clones (Kosmrlj, et al., 2008; Morris \& Allen, 2012). The consequence of such selection is something that has not been fully appreciated: After clonal selection, what remains, by default, are lymphocytes that express $T$ cell or $B$ cell receptors that mimic the range of host "self" antigens accessible to non-self molecules. In other words, the immune system creates a simplified molecular "body double" of the host that can decoy potential pathogens and toxins away from host cells and then neutralize or destroy them. As a consequence of forming this "body double" microbes evolve not only to mimic host antigens, but TCR and BCR as well (Root-Bernstein, 2016; Root-Bernstein, 2017; He, et al., 2015; Moise, et al., 2016). Microbial mimicry of the immune system itself is a particularly subtle and effective way to avoid immunological detection and processing (He, et al, 2015; Root-Bernstein, 2017).

Molecular mimicry and molecular complementarity already play prominent roles in some AD theories, of course. The molecular mimicry theory (Oldstone and Fujinami, 1985) is based on the proposition that many microbial antigens mimic host antigens so that an active immune response to the microbe may cross-react with the host causing disease. The anti-idiotype theory (Plotz, 1983; Bradley, 1984) is based on the observation that anti-idiotype antibodies (or anti-idiotypic T cells) are ubiquitous in AD. Most microbes use some cellular receptor or transporter to target their infection; activation of an idiotypic immune response to the microbial antigen will therefore prompt clonal expansion of BCR or TCR that mimic the host receptor or transporter; an anti-idiotype will mimic the microbe itself; thus, production of an active anti-idiotype response to a microbe could lead to AD against the cell type or tissue targeted by the microbe. However, it should be noted that the role of anti-idiotypes in autoimmunity has been debated since their discovery: Zanetti (1983) and others (Adelman, et al., 2007; Tzioufas \&, Routsias, 2010) properly pointed out that anti-idiotypes may increase or decrease pathogenicity depending on the state of the immune system more generally. 
I propose here that elements of both the molecular mimicry and anti-idiotype theories (as well as several others, such as the bystander, hidden antigen and epitope drift theories) are at play simultaneously in $A D$ and that by combining them in the context of the immune-system-as-body-double, one generates a powerful, coherent, and consistent theory. This integrated theory explains all of the experimental data and clinical observations currently known about $A D$ and all of the anomalous findings mentioned above concerning rarity of $A D$ compared with infection, multiple $A D$ tied to single microbes, sex-related risks, microbiome roles in $A D$, etc.

\section{Antigenic Complementarity Theory (ACT)}

Working from the observation that virtually all animal models of AD require two components, an "antigen" and an "adjuvant" (e.g., Cohen \& Miller, 1994) - exceptions will be discussed below - I assume that induction of every AD requires two components. I will, for simplicity, both call both "antigens" for reasons that will become obvious as I proceed. I assume further that these antigens are molecularly complementary. This assumption will also be justified below. Finally, I assume that the two antigens mimic host molecules (FIGURE 1).

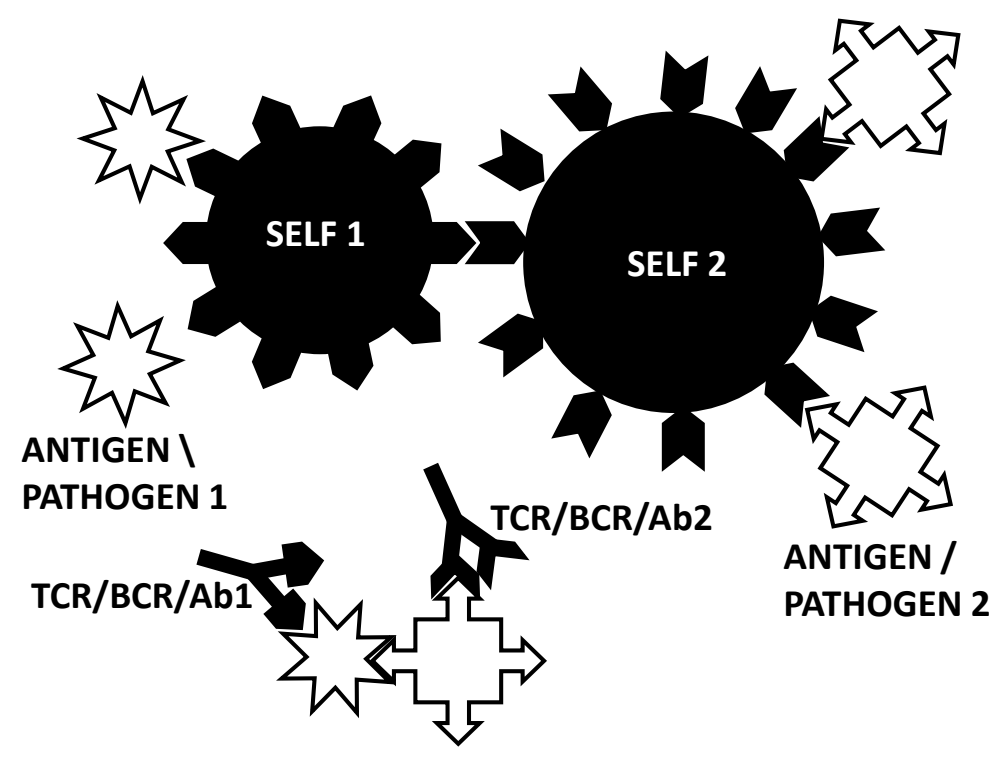

FIGURE 1: Organisms are comprised of interactomes based on molecularly complementary interactions between cells (Self 1 and Self 2). Microbes (Antigen/Pathogen 1 and Antigen/Pathogen 2) evolve to mimic host cellular receptors and transporters in order to recognize, enter and subvert the molecular machinery of specific cell types. The host responds by producing immune system molecules such as $T$ cell receptors, $B$ cell receptors and antibodies (TCR/BCR/Ab) that are molecularly complementary to the Antigen/Pathogens and capable of decoying and neutralizing the infectious potential of the Antigen/Pathogens. 
A series of implications follow logically from these three assumptions, which I will abbreviate under the name "antigenic complementarity theory" or ACT, and these are illustrated in TABLE 1 and FIGURE 2.

\section{TABLE 1: Key Epidemiological and Etiological Implications of ACT}

Individual agents will rarely correlate well with induction of any particular $A D$

Conversely, multiple agents will each correlate weakly with AD etiology

Specific combinations of agents will correlate far better than individual ones with $A D$ etiology

Different combinations of agents will be associated with different $A D$

Any given agent may be associated with multiple AD by means of combinations with different second agents.

Antibody or T cells might replace the complementary antigen in repeated infections with a single agent (the combination antigen-antibody or antigen-TCR representing a novel antigenic pair).

The rarity of onset of $A D$ in individuals is due to the rarity of particular combinations of agents co-occurring in any given individual.

TABLE 1 lists some epidemiological and clinical implications of ACT. The most important is that complementary antigens/pathogens contributed from independent sources such as a pair of concurrent or overlapping infections will induce a series of immunological responses that are not induced by single antigens/pathogens. An immune system faced with the necessity to address such complementary antigens will appear to malfunction in the sense of losing its ability to discriminate between "self" and "nonself", despite carrying out each of its normal functions properly. Figure 2 illustrates the series of conundrums that cause the appearance of malfunctioning and the induction of $A D$. 


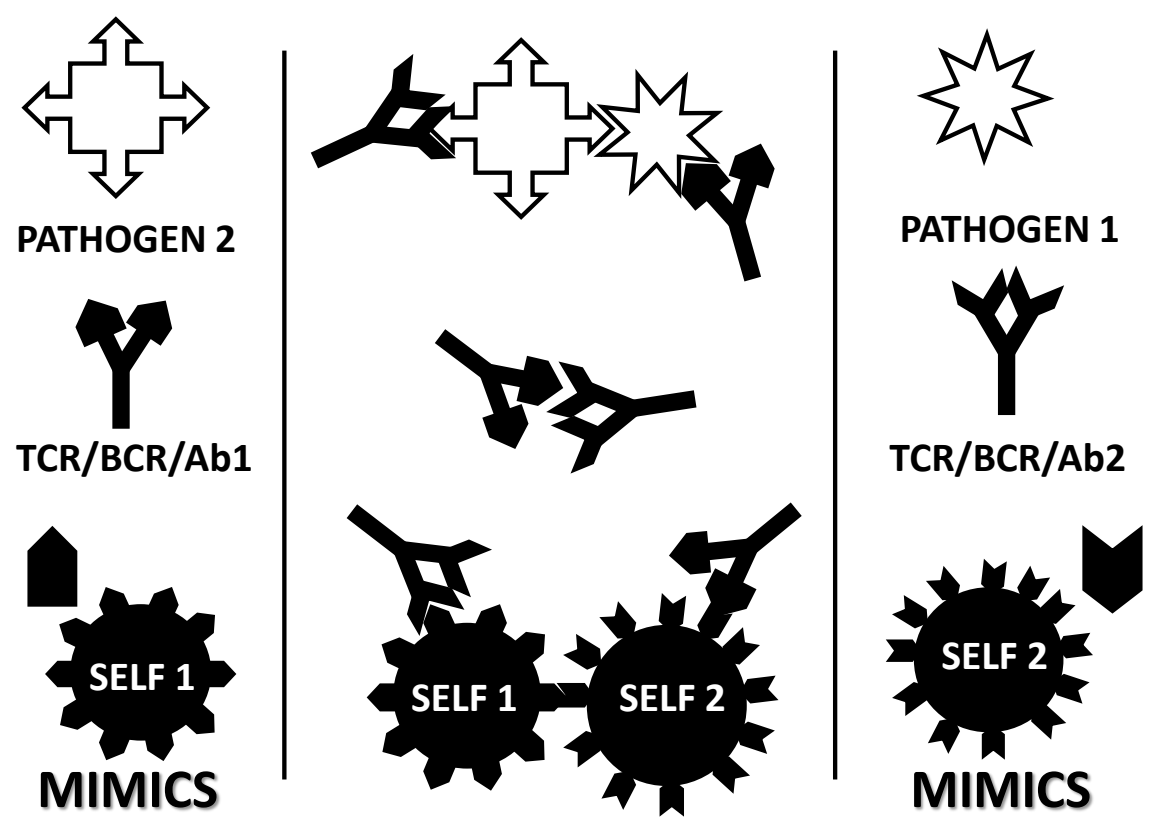

FIGURE 2: Imagine a host immunologically responding to a concurrent pair of pathogens expressing complementary antigens (Pathogen 1 and Pathogen 2). Imagine further that each of these pathogen antigens mimics a host antigen (Self 1 and Self 2 ). The antigens will each induce complementary $T$ cell receptor, $B$ cell receptor and/or antibody (TCR/BCR/Ab) responses but because the pathogen/antigens mimic Self 1 and Self 2, the complementary TCR/BCR/Ab responses will also recognize one of the Self antigens as a target. Each TCR/BCR/Ab response also mimics one of the Pathogen antigens so that each TCR/BCR/Ab recognizes the other as an antigenic target. The result is a civil war within the immune system itself that, because of Pathogen mimicry of Self spills over to host tissues. This model incorporates both the molecular mimicry theory of $A D$ as well as the anti-idiotype theory, but with a double twist involving two sets of molecular mimicry and the production of a pair of idiotypic responses that act like (but are not produced as) anti-idiotypic responses. All of these immunologic responses are "normal" and the results do not require the assumption of some error that "permits" tolerance to be abrogated in the induction of AD. What makes AD rare, according to this model, is the necessity for the host to encounter concomitant or overlapping, antigenically complementary pathogens.

Most importantly, the necessity of processing a pair of coincidental "self"-mimicking complementary antigens will force the immune system to break "self" tolerance. Each antigen induces a complementary immune response (whether T- or B-cell mediated). Because the antigens are themselves molecularly complementary ("antigenic complementarity"), the resulting immune responses will also be molecularly complementary to each other. In addition, each of the immune responses will now mimic one of the antigens so that the difference between "self" and "non-self" will be abrogated. The result will be the appearance of both cross-reactivity of the immune system to "self" antigens as in molecular mimicry theory and the concurrent production of what appears to be (but is not) an anti-idiotype 
response. These concurrent responses begin a "civil war" within the immune system itself that extends through molecularly mimicry to attack the host as well. All of this process will occur by means of normal immune responses without any "mistakes" or failures of the tolerance system.

The "civil war" posited by ACT begins with normal immune responses and proceeds to produce five unique outcomes. First, as has been known since Ehrlich's foundational experiments at the end of the $19^{\text {th }}$ century, that each antigen induces a complementary $T$ cell- and/or B-cell mediated response. In the case of the complementary infections posited here, each antigen mimics a host molecule, so each immune response will recognize a host molecule as a potential target. Everything that is known about molecular mimicry in AD therefore follows, but ACT proposes that there is more than one set of molecular mimicries occurring in every $A D$. Thus, from the perspective of $A C T$, all data supporting molecular mimicry theory (MMT) are valid, but MMT has focused on only half of the AD story. ACT requires a second, complementary antigen that induces its own complementary immune response. This second antigen may also mimic one or more host antigens.

Next, because the antigens are complementary, the pair of immune responses (whether T cellor B-cell mediated) will also be complementary to each other. In consequence, every AD will be characterized by the formation of what appear to be "anti-idiotypic" antibodies or T cell receptors (or both), but these "anti-idiotypes" will, in actuality, each be generated as primary, idiotypic responses. Thus, all evidence supporting a role for "anti-idiotypes" can be explained by ACT. ACT reinterprets these "anti-idiotypes" as dual idiotypic responses. When so-called "anti-idiotypes" arise matters: if they arise at the same time as the so-called idiotype arises, then this is evidence for ACT; if the anti-idiotype arises after the idiotype concentration peaks, then it likely to be a true anti-idiotype. Both scenarios may occur and the difference in timing might explain why it is sometimes observed that "anti-idiotypes" enhance pathogenicity the immune response in AD while sometimes moderating it (Zanetti, 1983; Adelman, et al., 2007; Tzioufas \&, Routsias, 2010). I predict that complementary idiotypes cause pathogenicity, while true anti-idiotypes are generated to moderate $A D$.

Third, the presence of pairs of idiotypic, complementary immune responses will lead to the formation of either circulating immune complexes (CIC) (if the components are antibodies) or perivascular cuffs (if the components are lymphocytes) or both. This prediction of ACT uniquely differentiates it from all other $A D$ theories, none of which can explain the nearly ubiquitous presence of high levels of $\mathrm{CIC}$ and/or of perivascular cuffing in $\mathrm{AD}$. Moreover, in addition to the usual types of antibody-antigen CIC, complementary (supposedly idiotype-anti-idiotype) antibodies occur in a wide range of AD (Morgan, et al., 1979; Rose, et al., 1982; Simpson, et al., 1983; Zanetti, 1986; LebrunGrandie, et al., 1987; Bergonzi, et al., 1987; Jackson, 1988; Nordstrom, et al., 2000; Tincani, et al., 2006). If ACT is correct, $\mathrm{CIC}$ should contain two complementary antigens and their complementary antibodies, a prediction that has been satisfied for systemic lupus erythematosis (SLE), in which CIC have been found to contain not only DNA antigen and anti-DNA antibodies but also HMBG1, a DNA-binding protein involved in transcription regulation, and antibody to HMBG1 (Pisetsky, 2007; Tian, et al., 2007). A similar situation exists in type 1 diabetes mellitus (T1DM), in which antibodies to both insulin and its receptor (which are obviously complementary to each other) as well as to glucagon (which is complementary to insulin) are present, and the complementary pairs of antibodies precipitate each other (Root-Bernstein 
\& Dobbelstein, 2001). Moreover, TCR in T1DM also express complementary sequences that mimic insulin, its receptor and glucagon; these TCR sequences bind to each other; and the TCR are targets for T1DM autoantibodies (Root-Bernstein \& Podufaly, 2012). Such anti-idiotype T cells are known to exist, but have not, apparently, yet been documented in AD perivascular cuffs. Their presence is a unique, testable prediction made by ACT.

Fourth, perhaps the most unusual prediction stemming uniquely from $A C T$ is that the sequences of the $T$ cell receptors or antibodies generated in an AD can identify the antigens or pathogens that initiated the disease. Because each antigen or pathogen induces a complementary immune response, and the antigens are complementary, the immune responses will also be complementary. In consequence, the immune response to one antigen will mimic the second antigen and the immune response to the second antigen will mimic the first (see FIGURE 2). As noted in the previous paragraph, such relationships between immune responses and complementary antigens have already been identified in SLE and T1DM. It should therefore be possible to use the sequences of TCR or antibodies up-regulated during $A D$ to identify, through proteonomic similarity searching, the initiating antigens (Root-Bernstein, 2016; Root-Bernstein, 2017). Since TCR sequences may, themselves, be used as therapeutic vaccines for AD (Vandenbark, et al., 1989), such information may be of direct practical application in the design of new AD treatments. Again, this prediction is unique to ACT and does not follow from any other theory of $A D$.

Fifth, ACT provides a specific mechanism, based on normal immunologic function, for breaking tolerance during the induction of $A D$. Presentation of a pair of complementary antigens to the immune system requires it to respond with complementary antibody or T cell responses. Each of these responses mimics the complementary antigen (see FIGURE 2). Thus, each immune response also becomes an antigen for the other, acting like idiotype-anti-idiotype pairs, even though each response is actually idiotypic. Moreover, since each antigen mimics a host molecule, each idiotypic immune response will potentially recognize a host molecule. Thus, complementary antigens that mimic host molecules will drive the production of host-cross-reactive, complementary idiotype-idiotype immune responses that not only induce a civil war within the immune system, but one that engages host tissues as well. Additionally, as I will discuss below, because the microbiome evolves to mimic host antigens (including the host's TCR repertoire), the civil war can expand to (or from!) the microbiome.

In sum, ACT provides novel, testable explanations of how normal adaptive immune responses that break tolerance and trigger pathological consequences. However, the adaptive responses are only a small part of the unusual consequences that complementary antigens initiate.

\section{ACT, Altered Antigen Processing and the Abrogation of "Self-Tolerance"}

Antigenic complementarity not only induces complementary immune responses that will fool the immune system into attacking itself and its host, it also provides a mechanism for altering antigen processing and thereby bypassing natural tolerance mechanisms. It is well known that molecules to which the immune system is tolerant can be made antigenic through chemical or physical alteration and that non-antigens can be made antigenic by chemically coupling them to an antigen or hapten (e.g., 
Landsteiner and van der Scheer, 1936; Eisen, et al., 1952). The formation of complementary antigen complexes can have the same effects (reviewed in Root-Bernstein, 2015).

Antigen processing begins with the uptake of potential antigens by macrophages, dendritic cells and other monocytes through various endocytotic and translation mechanisms that bring material into the cytosol where the material is enzymatically degraded. The degraded compounds are then sampled by major histocompatibility (called, in Homo sapiens, human leukocyte antigen) proteins (MHC/HLA). Degraded material that is recognized by MHC/HLA is then presented on the cell surface where the MHC/HLA-antigen complex can be recognized by an appropriate $T$ cell receptor, resulting in the activation of an immune response (Blum, et al., 2013). Unfortunately, many of the details of antigen processing and presentation remain unclear, including the mechanisms governing which degraded material needs to be presented on the cell surface and the role of Toll-like receptor activation in regulating the process (Vyas, et al., 2008). Despite the uncertainties in the details of the process, it seems likely that in $A D$, altered antigen processing may present to the immune system self-mimicking antigen fragments that are not normally "seen" as antigenic. Complexation can alter the processing and presentation of molecules that would normally be treated as non-antigens. Two examples are illustrative.

One example involves insulin and glucagon. Neither compound is normally processed as an antigen but become so when presented to the immune system together. Insulin and glucagon are molecularly complementary, binding to each other with about 0.9 micromolar affinity (Root-Bernstein and Dobbelstein, 2000; Dillon, et al., 2006). Since the active concentrations of these hormones are normally in the nanomolar range, they do not normally form a complex in vivo and neither hormone is processed as an antigen under normal physiological conditions. Starting in 1928, however, it was recognized that diabetics receiving insulin injections, the concentrations of which approach $1 \mathrm{mM}$, often developed anti-insulin antibodies. While some of the antigenicity involved amino acid variants present in the bovine and porcine insulins used at that time, the main antigenic determinant was the presence of $1-2 \%$ contamination by other proteins. Chance, et al. (1976) fractionated these antigenic insulin preparations, demonstrating that the antigenicity of the insulin was due to glucagon contamination. Adding an equal amount of glucagon to insulin drops the dose required to induce insulin antibody by more than a 1000 -fold (Root-Bernstein \& Dobbelstein, 2000). Notably, the insulin-glucagon complex significantly retards proteolytic digestion of the components and modifies the resulting fragmentation (Foa, 1962).

The second example involves the use of antigen-antibody complexes to enhance antigenicity and modify what epitopes are targeted. The earliest use of this strategy involved the production of a partially neutralized complex composed of diphtheria toxin and its antitoxin for use as a vaccine against diphtheria infections (Rhoads, 1928). Diphtheria toxin is not antigenic in human beings at any dose that they can tolerate (Pappenheimer and Uchida, 1972), so to protect patients, the toxin needed to be partially neutralized. Antitoxin (antibody produced in horses or goats) provided the neutralization, simultaneously increasing antigenicity. An unfortunate side-effect of this toxin-antitoxin vaccine was to induce a Guillain-Barré-like syndrome in some recipients (e.g., Delp, et al., 1946; Jamieson, 1947). This phenomenon was then harnessed by immunologists to create one of the first autoimmune disease 
models for peripheral neuropathies (Muller, 1954; Waksman, et al., 1957). The strategy of combining antigens with antibodies has been used ever since as a method of specifically inducing enhanced antigenicity and to modify or alter which epitopes of a complex antigen are preferentially presented to the immune system (e.g., Manca, et al., 1988; Randall and Young, 1988; Bouige, et al., 1996; Oli, et al., 2004; Isoda, et al., 2007; Hioe, et al., 2009). AD models induced by covalently tethering an antigen to its complementary MHC or TCR involve similar molecular complementarity and fit the altered antigen processing model just described.

Altered antigen processing of complementary antigens can explain six phenomena that are otherwise left puzzling by other theories of $A D$ causation. These are: the correlation of individual infectious agents with multiple $A D$; the question of how multiple injections of alloantigens can sometimes induce $A D$ in animal models; why adjuvants are required to induce most animal models of $A D$; why one adjuvant can only rarely be substituted for another in animal models of $A D$; and how complex adjuvants, such as Freund's complete adjuvant, can aid in the induction of multiple AD.

Altered antigen processing for specific pairs of infectious triggers addresses the problem of how individual microbes might produce different AD. For example, coxsackieviruses are associated with at least four AD: type 1 diabetes mellitus (Drescher, et al., 2015), autoimmune myocarditis (Rose, 2008), Sjogren's syndrome (Triantafyllopoulou, et al., 2004) and polymyositis (Strongwater, et al., 1984). Human cytomegalovirus (CMV) is associated with onset of systemic lupus erythematosus (SLE), systemic sclerosis (SSc), diabetes mellitus type 1, and rheumatoid arthritis (RA) (Halenius \& Hengel, 2014). Similarly, type A streptococcal infections are associated with rheumatic heart disease and Pediatric Autoimmune Neuropsychiatric Disorders Associated with Streptococcal infections (PANDAS) (Cunningham, 2016), Sydenham's chorea (Cutforth, et al., 2016), reactive arthritis and glomerulonephritis (Ivory \& Folzenlogen, 2009). No current theory explains how one disease agent can produce a range of diverse autoimmune sequelae. ACT proposes that different combinations of infectious agents will produce different sequelae by means of the complementarity between different epitopes and the differential antigen processing of their resulting antigenic complexes.

Because complex antigens such as microbial pathogens have multiple epitopes, they will also have multiple antigenic complements. Different pairings of antigens should lead to different AD by altering antigen processing in different ways, thereby leading to the display of different epitopes on different MHC to different TCR or BCR (FIGURE 3). Thus, for example, a complex between coxsackievirus might, when paired with a streptococcal infection lead to myocarditis, while coxsackievirus complexed with Clostridium to type 1 diabetes mellitus, and with some other bacterium or virus to myositis or Sjogren's syndrome (Root-Bernstein, 2016).

Indeed, something like this is observed with Freund's complete adjuvant (FCA), which, by itself, can induce adjuvant arthritis (AA), but in combination with other antigens, induces a range of quite disparate experimental autoimmune diseases. The same dose of FCA that can induce AA when combined with myelin basic protein, induces EAE without any AA pathology (Kies, et al., 1975); with thyroglobulin, experimental autoimmune thyroiditis, without any AA pathology (Sakata, et al., 1985); with acetylcholine receptor, experimental autoimmune myasthenia gravis (EAMG) without any AA pathology (Robinet, et al., 2017); with streptococcal M protein or cardiac myosin, experimental autoimmune myocarditis (EAM) without any AA pathology (Gorton, et al., 2010). Moreover, the arthritis-inducing component can be "masked" in the presence of measles virus, or by a single 
decapeptide derived from measles virus, so that no AA results from an FCA injection (Root-Bernstein, 2009). Each of these models demonstrates the proposition that the same complex antigen can play different roles in different $A D$, a phenomenon that would seem to be inexplicable unless adding various peptides and proteins alters antigen presentation and processing.

Indeed, studies of FCA components demonstrate that different ones are involved in different $A D$. AA in rodents turns out to be due to two specific, synergistic components, a water-soluble arthritogenic and immunogenic component (WAC) and a lipophilic component, waxD, which are effective in combination but not separately. The lipopolysaccharide (LPS) and purified protein derivative (PPD) components of CFA cannot replace the waxD component, nor can pertussis vaccine replace FCA (Koga, et al., 1976). In EAE, the active component of CFA is the NOD2 activator, muramyl dipeptide (Audibert, et al., 1977); in EAMG, the active component of CFA is the TLR4 activator, lipopolysaccharide (LPS) (Robinet, et al., 2017); LPS is also the active component in the induction of thyroglobulin-induced EAT (Ciháková, et al., 2004). In none of these cases can incomplete Freund's adjuvant (lacking the Mycobacterial component) support induction of the AD.

In keeping with ACT, I propose that so-called "adjuvants" are complementary to the antigens they potentiate. This complementarity can be demonstrated by the formation of stable complexes (i.e., through physicochemical binding studies). Such complexes either directly, or indirectly, alter antigen processing. The necessity for forming such stable complexes may explain why stable emulsions of "adjuvant"-antigen mixtures are required for the induction of most experimental AD. Such binding has only been demonstrated directly in handful of cases. In one, muramyl dipeptide ("adjuvant peptide") forms a complex with the encephalitogenic region of myelin basic protein (MBP) both in water and in oil-water emulsions (Root-Bernstein and Westall, 1983; Root-Bernstein and Westall, 1990). While the combination of adjuvant peptide with MBP induces experimental allergic encephalomyelitis in rats if antigen and adjuvant are inoculated in a stable emulsion together, separating the inoculation of antigen and adjuvant in either space or time results in decreased EAE induction (Waksman, 1980) and sufficient separation in time results in failure to produce disease (e.g., Weigle, 1980; Sakata, et al., 1985; Heeger, et al., 2000), a phenomenon that is generally observed in many models of AD such as experimental autoimmune thyroiditis (Kong, et al., 1982; Lewis, et al., 1987) and experimental systemic lupus erythematosus (Isenberg, et al., 1991). I would also argue that glucagon is playing the role of an "adjuvant" for insulin, and antitoxin for pertussis toxin, in the examples described above, and in both cases direct binding of the antigen pairs has been demonstrated.

The altered-antigen-processing mechanism permits some exceptions to complementary-antigen induction of autoimmunity for cases of repeat inoculations and chemically- or physically-altered antigens. Chemical or physical alteration of antigens will alter their processing and presentation to the immune system and non-antigens can be made antigenic by chemically coupling them to another antigen or hapten (e.g., Landsteiner and van der Scheer, 1936; Eisen, et al., 1952). More significantly in the present context, antibody-antigen complexes may also explain how some animal models of AD can be induced by multiply-inoculating an animal with the same antigen repeatedly over a period of weeks or months (Eaton \& Almquist, 1977; Törmäkangas, et al., 2005; Shigemoto, 2007). I propose that following sufficient tissue damage associated with repeated inoculations of an antigen, sufficient antibody is produced to create an antibody-antigen complex, which is the actual inducer of the autoimmune disease process. 
This conjecture regarding specific binding of adjuvant to antigen may offend purists who will point out that an adjuvant is, by definition, a "non-specific immune potentiator", emphasis on "nonspecific". Surely, one might object, an adjuvant cannot be non-specific and yet display specific complementarity to a particular antigen. However, in the induction of $A D$, adjuvants rarely, if ever, play a non-specific role. For example, induction of rheumatic heart disease often involves a combination of Streptococcal M protein (or its mimic, cardiac myosin) with Freund's complete adjuvant (FCA), a mixture of killed mycobacterial antigens in mineral oils. Gorton, et al. (2010) attempted to replace FCA with either Emulsigen ${ }^{\circledR}$ or Montanide ISA50V without success. In EAE, Lederer and Chedid isolated muramyl dipeptide ("adjuvant peptide") as the minimal structure that can replace FCA when combined with myelin basic protein (MBP) for guinea pigs. The lipopolysaccharide (LPS), purified protein derivative (PPD) and waxD components of CFA could not replace adjuvant peptide, nor could pertussis vaccine. Subsequent experiments demonstrated that the adjuvant peptide itself could not be modified without losing its ability to support the encephalitogenicity of MBP (Audibert, et al., 1977). Similarly, in the production of experimental systemic lupus erythematosis, the bacterial superantigens (SAgs)

Staphylococcal Enterotoxin B (SEB), Toxic Shock Syndrome Toxin-1 (TSST-1) and Mycoplasma Arthritidis Mitogen (MAM) were unable to replace FCA (Baharav, et al., 1996). Similar results were subsequently found for experimental autoimmune thyroiditis (EAT), although in this instance adjuvant peptide and its modified versions were not active (Kong, et al., 1985). EAT is caused by a combination of thryoglobulin with either FCA or LPS (Ciháková, et al., 2004). Chemical modification of LPS also destroys its EATenabling activity (Kong, et al., 1985). In another set of experiments, LPS could be substituted with SGP (a synthetic copolymer of starch, acrylamide, and sodium acrylate) but not with the adjuvant Quil A (a plant saponin) (Williams, et al., 1987). In sum, I propose that "adjuvants" are never "non-specific" in experimental $A D$, but support altered antigen presentation and processing through complexation with the so-called "antigen".

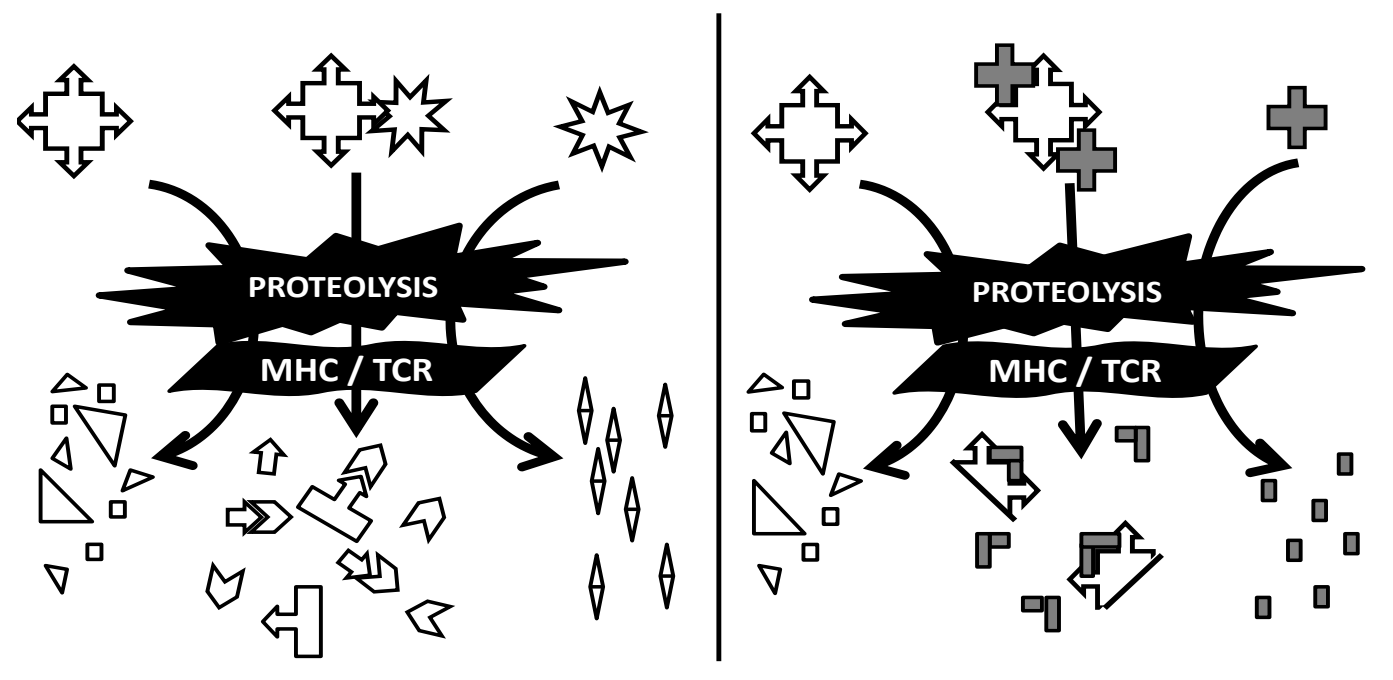


FIGURE 3: Summary of how complementary antigens might alter antigen processing and presentation. Imagine that two microbes are independently processed by antigen-presenting cells (left). Each microbe will be proteolytically digested and some subset of the fragments presented by appropriate MHC/HLA on the cell surface (bottom left). If, however, both antigens are processed in tandem, then the proteolytic digestion will be modified and a different set of antigenic fragments expressed by MHC/HLA on the cell surface. Because microbes are molecularly complex, the same microbe might pair with a different set of complementary molecules on a microbe different than the one considered first (right). In consequence, proteolytic digestion of the microbial antigens will be altered and a different set expressed on the cell surface by MHC/HLA. In this way, one microbe might be epidemiologically and etiologically associated with more than one $A D$, yet affect very different tissues or organs.

My hypothesis is testable. I propose that complementary antigens form complexes that alter antigen presentation and processing in ways that reveal otherwise hidden or destroyed epitopes. Complex antigens, such as bacteria or viruses, have a sufficient diversity of epitopes to support a variety of complementarities with other microbes so that any given microbe might induce more than one AD depending on the identity of the complementary infection and the sets of molecular mimicries they express with their host.

\section{ACT and Genetic Predisposition to Autoimmune Diseases}

The altered antigen processing mechanism is consistent with, but adds no new insight to, what is known about genetic predispositions to various AD. The vast majority of genetic mutations associated with increased risk of particular $A D$ involves antigen processing and display and most particularly the MHC/HLA system (e.g., Hotta-Iwamura, et al., 2016; Fernando, et al, 2008; Tochimoto, et al., 2015; Yarwood, et al., 2016; Huber, et al., 2008). Mutations in MHC/HLA would be likely to alter processing and presentation of antigens so that they induce host-cross-reactive immune responses. Similarly, genetic variants of immune regulatory proteins such as CD40, CD25, CD69, CTLA4, CCR3 and CCR5 are also known to increase susceptibility to various $A D$ presumably by interfering with normal tolerance mechanisms (Tomer, 2010; Zagoriti, et al., 2013; Parkkola, et al., 2017). Genetic mutations in the innate immune system can also modify how sensitive the system is to any particular type of microbial antigen (Delgado-Vega, et al., 2010).

\section{ACT Explains How Innate Activation Is Required for AD Initiation and Persistence}

All $A D$ are characterized by increased innate activation and hyperinflammation throughout the disease process (Papadimitraki, et al., 2007; Waldner, 2009; Li, et al., 2009; Mohammad Hosseini, et al., 2015) although the role of innate immunity in supporting AD development is far from clear (Duffy \& O'Reilly, 2016). This innate activation is initiated by foreign antigens, but maintained by host antigens once autoimmunity has been induced (Papadimitraki, et al., 2007; Waldner, 2009; Li, et al., 2009; Mohammad Hosseini, et al., 2015; Tomer, 2010). The innate system is basically comprised of pattern recognition receptor (PRR)-bearing cells that recognize pathogen-associated molecular patterns (PAMP) on microbes by means of a set of Toll-like receptors (TLR) and nucleotide-binding oligomerization 
domain-containing proteins (NOD) (Moreira \& Zamboni, 2012). Each TLR or NOD recognizes a particular class of viral or bacterial PAMP to up-regulate production of various inflammatory cytokines by means of either the TRIF (and/or TIRAP) or MyD88 pathways (FIGURE 4). TRIF stands for "Toll/IL-1 receptordomain-containing adaptor protein inducing INF- $\alpha$ activators" and, as its name says, the TRIF pathway results in the production of interferons (INF). TIRAP is the Toll/IL-1 receptor-domain-containing adaptor protein and activates a pathway releasing interleukins. MyD88 is the myeloid differentiation primary response protein 88 , which activates the release of NF-KB (nuclear factor kappa-light-chain-enhancer of activated B cells). TLRs 3 and 6 activate TRIF and therefore cellular (Th1) immunity; TLRs 1,2,4,5,7,8,9 and 11 activate MyD88 and therefore antibody-mediated (Th2) immunity (Mohammad Hosseini, et al., 2015). The essential role of innate immunity in the development and ongoing support of $A D$ pathogenesis is further demonstrated by the effectiveness of anti-TLR ligands as AD treatments (Barrat \& Coffman, 2008; Peón, et al., 2017; Dixit, et al., 2017).

Ongoing innate activation exposes serious lacunae in existing theories of $A D$ for two distinct reasons. Although innate activation is known to be essential for $A D$ development, no current $A D$ theory, other than the bystander theory, incorporates innate activation explicitly into its explanation of disease induction. The bystander theory is based on the observation that activated T cells rapidly die after the triggering antigens are removed, whereas an unrelated infection can provide ongoing stimulation via cytokine production that maintains their viability (Serreze, et al., 2000; Mitchell, et al., 1999; von Herrath, et al., 2003). Thus, initiation of an AD by one infectious agent could be supported by an unrelated infection.

However, no theory, including the bystander theory, explains how innate activation is maintained throughout the disease process. After all, once the primary infection and its bystander infection are both resolved, then one would expect immune activation should return to normal and tolerance mechanisms to come into play once again.

ACT incorporates the bystander theory by positing synergistic activation of innate immunity by complementary host antigens and CIC. ACT also resolves the ongoing-immune-activation problem by proposing that $\mathrm{CIC}$ as well as host antigens continue to stimulate synergistic innate responses. Some of these synergisms result in hyperactivation of either the TRIF or MyD88 pathway, while others activate both the TRIF and MyD88 pathways simultaneously, resulting in synergistic production of interleukins, interferons and NF-KB. In some animal models of $A D$, this dual activation is required to induce disease (e.g., Wang, et al., 2002). Because complementary self-antigens and CIC are continuously present, bystander activation of both innate and adaptive immunity are continuous. Thus, ACT proposes that complementary antigens are necessary not only to initiate autoimmunity in the adaptive immune system, but to support both the initial activation and continuing inflammatory processes for the duration of the $A D$.

As in the adaptive immune system, complementary antigens are crucial altering the normal function of the innate immune system in AD. ACT proposes that complementary antigens stimulate complementary, synergistic innate mechanisms. Synergisms are well-documented within the innate immune system and include TLR2 with TLR3; TLR2 with TLR4; TLR2 with TLR6; TLR 3 with TLRs 7 and 8; 
TLR 4 with TLR 8 and 9 (Sato, et al., 2000; Napolitani, et al., 2005; Ghosh, et al., 2007; Krumbiegel, et al., 2007; Vanhoutte, et al., 2008; Mäkelä, et al., 2009; Lee, et al., 2016; Acharya, et al., 2016; Fischetti, et al., 2017; Nouri-Shirazi, et al., 2017). For example, TLR2 and 4 synergize in rheumatoid arthritis-derived synoviocytes (Jung, et al., 2007; Liu, et al., 2014), sarcoidosis (Wikén, et al., 2009), systemic lupus erythematosus, systemic sclerosis, Sjogren's syndrome, psoriasis, multiple sclerosis, and autoimmune diabetes (Liu, et al., 2014). In addition, TLR3, TLR4 and TLR9 also synergize with NOD1 and NOD2 in dendritic cells to induce gamma-IFN and IL-12 (Fritz, et al., 2005; Tada, et al, 2005; Takada \& Uehara, 2006; Farzi, et al., 2015).

Few TLR antagonisms have so far been reported: TLR 2 agonists block subsequent activation of TLR3 and TLR4, presumably through a down-regulation mechanism (Re and Strominger, 2004); TLR 7 and 8 agonists similarly antagonize TLR 9 agonists (Ghosh, et al., 2007). These results suggest that timing of TLR activation is important: co-stimulation with TLR2-3 and TLR2-4 is synergistic (see previous paragraph), yet TLR2 followed by TLR3 or TLR4 is antagonistic. A negative feedback loop between TLR means that the effects of combined infections will differ according to when they stimulate innate immunity. Concomitant exposure is likely to synergize; sufficiently time-separated exposure is likely to antagonize.

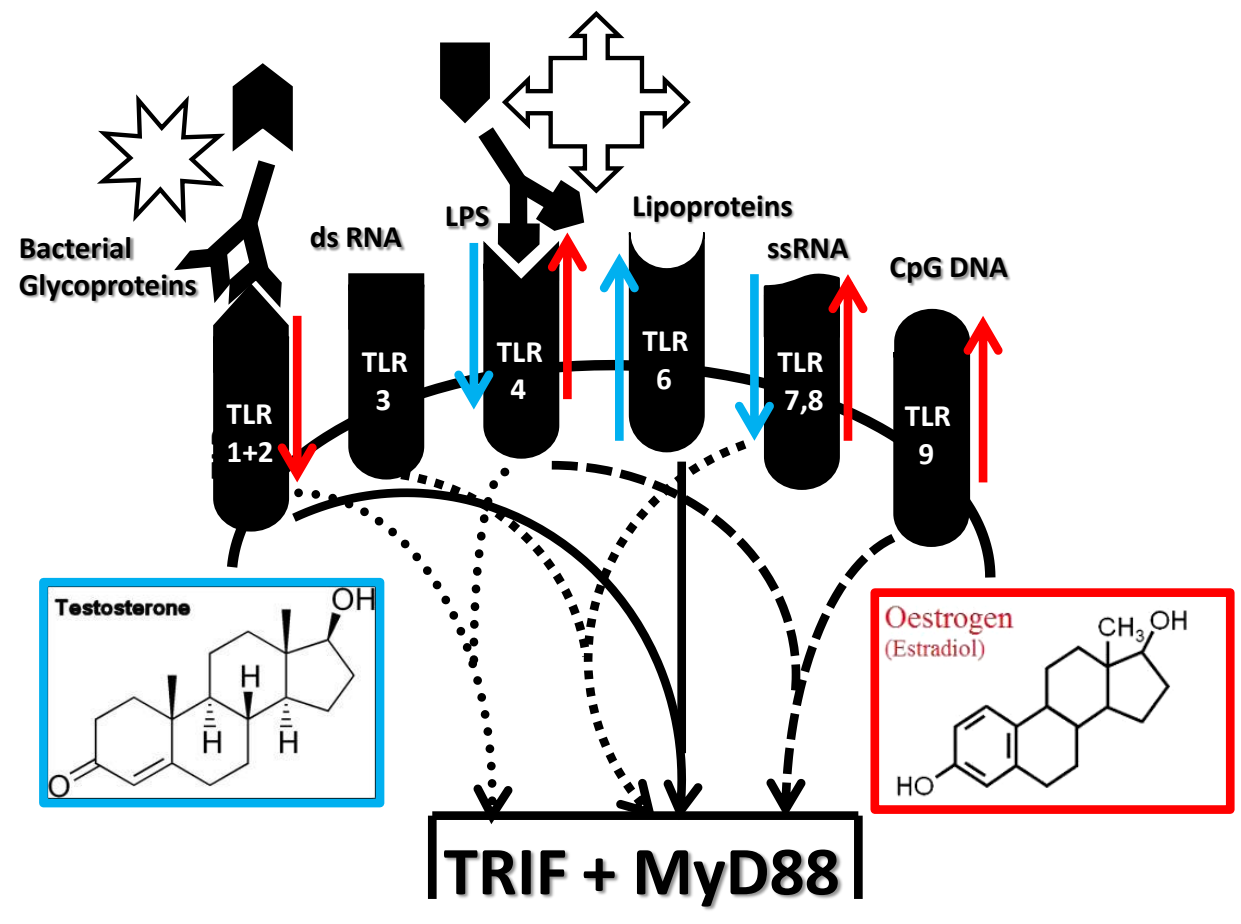


Complementary antigen-induced TLR synergism (or TLR-NOD synergism) explains many aspects of $A D$ pathogenesis that are otherwise problematic or simply ignored by other theories of $A D$. These include why specific "adjuvants" are required to initiate animal models of AD; how hyperactivation of the innate immune system is initiated; how hyperactivation of innate immunity is maintained throughout an AD; and why such hyperactivation is always associated with the activity or more than one set of TLR and/or NOD.

First, to return to the issue of why one "adjuvant" is rarely substitutable by another in the induction of animal models of AD (see ACT and Altered Antigen Processing section above), ACT proposes that $A D$ only follow the activation of synergistic pairs or sets of TLR or NOD. Different adjuvants often activate different TLR or NOD. Only those substitutions preserving complementarity activation of correct sets of innate mechanisms will support any given $A D$. This mechanism explains why one of the "holy grails" of the molecular mimicry theory has never been achieved. This "holy grail" is to initiate an AD using a purified molecular mimic of a host antigen. For example, the Salk lab spent years attempting to induce EAE with purified myelin basic proteins inoculated in many different dosages, repetitions and routes, without success (Salk, et al., 1980). Adjuvants of some type were required. In the forty years since, no one has yet succeeded in inducing any other experimental AD model with a pure molecular mimic either, and I would predict, based on ACT, that no one ever will. Purified molecular mimics require so-called "adjuvants" to induce the proper synergistic stimulation of innate immunity (e.g., Tsuji, et al., 2012). Because only certain TLR and NOD synergies exist (TLR2-TLR4, TLR3-TLR7, etc.), "adjuvants" must be tailored to their "antigens" by molecular complementarity and the resulting antigenic complementarity is mirrored in terms of TLR-NOD complementarity.

Complementary-antigen induced innate immunity can explain how hyperactivation of the immune system is maintained after the initiating antigens are eliminated. As noted above, hyperactivation of innate immunity is present at least periodically, if not continuously, throughout the course of $A D$. While the bystander theory can explain how such innate hyperactivation is initiated by the presence of a bystander infection, it leaves mysterious the means by which continuing innate activation is achieved once the bystander infection is eliminated. ACT proposes that ongoing hyperactivation of innate immunity results from three sources. One are $\mathrm{ClC}$, which are known to activate TLRs 7,8 and 9 (see above). A second is the release of pairs of complementary host antigens from cells, organs or tissues that are attacked during the process of the AD. These pairs of host antigens each mimic one of the initiating microbial antigens and would therefore be expected to synergize in the same way. In addition, ACT proposes that because each adaptive immune response mimics one of the microbial antigens that triggered the $A D$, each immune response will also be able to stimulate innate immunity as well.

Complementary pairs of adaptive immune responses will therefore drive synergistic innate immune responses. A normally functioning immune system that must respond to a pair of complementary antigens that mimic the host will therefore be forced to induce complementary adaptive immune responses that not only cross-react with host antigens, but also drive ongoing innate hyperactivation. Innate hyperactivation, in turn, drives increased adaptive immune responses as a result 
of the cytokines and lymphokines produced. A vicious cycle results, consisting of a positive feedback system that maintains hyperinflammation of both innate and adaptive immunity.

If TLR (and/or NOD) synergism is required to initiate and support ongoing AD development, then many aspects of experimental and clinical research need to be refocused since most efforts are currently on identifying individual TLR that predispose to any given AD. For example, Assmann, et al. (2015) and McCall, et al. (2015) have argued strongly that TLR3 underlies development of T1DM, while Devaraj, et al. (2008) and Itoh and Ridgeway (2017) have argued that TLRs 2 and 4 are essential. Evidence also implicates TLRs 1, 7 and 9 (Tai, et al., 2016; Lein and Zipris, 2009). In light of the known TLR synergisms summarized above, combinations of TLRs 2 and 4, 3 and 7, and/or 4 and 9 would each result in hyperactivation of innate immunity and TLR3 activation would be necessary to induce cell-mediated immunty. The activation of multiple synergistic pathways would obviously be even more inflammatory. Thus, synergistic pathways need to be explored more fully as required enablers of AD.

\section{ACT Explains How Sex Alters AD Risk and Why Some AD are Male Dominant}

Current theories of AD such as molecular mimicry theory, bystander effect theory, aberrant clonal deletion theory, etc., are universally incomplete in being unable to explain, within the theory itself, how sex alters $A D$ risk. By integrating innate immunity effects into its explanation of $A D$ causation, $A C T$ is able to shed new light on this phenomenon.

Sex affects the probability of developing any particular AD both in human patients and animal models. Taking all AD into account, women are about three times more likely to be affected than men (Fairweather and Cihakova, 2009; McCombe, et al., 2009; Nussinovitch and Shoenfeld, 2012), and in some cases, such as SLE, Sjogren's syndrome and autoimmune thyroiditis, women may develop the disease as much as ten times more often than men. However, there are exceptions: men develop ankylosing spondylitis, Goodpasture's syndrome, autoimmune myocarditis, alopecia areata, and type 1 diabetes mellitus more often than women (Fairweather, et al., 2008; Ngo, et al., 2014), while vitiligo, ulcerative colitis, and Crohn's disease occur about equally in the two sexes (Ngo, et al., 2014; McCombe, et al., 2009). Sex hormones can moderate AD progression through a number of possible mechanisms including epigenetic ones, the modulation of $\mathrm{T}$ and $\mathrm{B}$ cell numbers, stimulation of myeloid precursor development (Kovats, 2015) and direct influences on innate immune responses (Fairweather and Cihakova, 2009; Rubtsova, et al., 2015; McCombe, et al., 2009; Nussinovitch and Shoenfeld, 2012). I will focus on the latter here because sex hormones can affect innate immune responses in ways that have not been appreciated fully in the context of the TLR and NOD synergisms reviewed in the previous section.

In suggesting that $A D$ result from the synergistic actions of complementary infections, ACT sheds a novel light on the ways in which sex may alter the modulation of innate immunity. Oestrogens preferentially up-regulate the expression and activity of TLRs 4, 8, and 9 (Svenson, et al., 2014; Laskari and Anumba, 2017; Young, et al., 2014; Young, et al., 2017) and down-regulate the function of TLR 2 (Dasgupta and Eudaly, 2012; Li, et al., 2016; S Lashkari and Anumba, 2017). In consequence, the synergisms of TLRs 2 and 4,4 and 8, and 4 and 9 described above (and illustrated in FIGURE X) will all be enhanced in the presence of oestrogens. Testosterone, in contrast, preferentially up-regulates TLR 6 and down-regulates the function of TLRs 4 and 8 (Al-Quraishy, et al., 2014). The synergisms of TLRs 2 and 4, 4 and 7,4 and 8 , and 4 and 9 will all be blunted. Thus, women will be more likely than men to develop AD under most circumstances because women will experience sex hormone-amplified support of their 
hyperinflammatory state. Thus, ACT predicts that in female-dominant AD, the triggering antigens will activate various combinations of TLRs 2, 4, 7, 8 and 9 .

In male-dominant $A D, A C T$ predicts that different sets of TLR will be activated that involve testosterone stimulation of their activity. Testosterone specifically enhances TLR 6 expression and function (Park and Choi, 2017; Al-Quraishy, et al., 2014). Thus, synergisms involving TLR6 (e.g., TLR 6 with 2) (see above and FIGURE X) should produce hyperinflammatory conditions that could support AD preferentially in males.

Notable, some combinations of TLR activation are not (yet, at least) known to be enhanced or blunted by sex hormones (e.g., TLRs 1, 3 and 5), so that AD triggered by antigens that stimulate these innate responses would be expected to occur at equal rates among men and women.

The specific sets of TLR activated by infectious triggers in each AD should provide a test of whether the predictions made by ACT are correct concerning the mechanism by which sex hormones modify AD risk. A further test concerns what type of adaptive immunity is supported by differential hyperactivation of innate immunity. AS Fairweather, et al. (2008) have pointed out, male-dominant AD are characterized by Th1 (cell-mediated) immunity, whereas female-dominant AD are characterized by Th2 (antibody-mediated) immunity. Thus, a second testable aspect of the TLR-enhancement mechanism proposed here is that the specific sets of TLR (and NOD) that are activated in tandem should induce cytokine responses that preferentially activate either Th1 or Th2 immunity. Most TLR-TLR and TLR-NOD synergisms would be expected to enhance antibody-mediated immunity via enhancement of the MyD88 pathway. Exceptions would be combinations involving TLR3 and TLR6, which stimulate cellular (Th1) immunity (Mohammad Hosseini, et al., 2015); notably, TLR6 is also up-regulated by testosterone. Thus, antigen combinations that involve TLRs 3 and 6 should be more likely in male-dominant AD. Notably, T1DM, which is a male-dominant and cell-mediated AD is thought to be supported by a combination of (synergistic) TLR3-TLR7 or TLR3-TLR9 activation (Tai, et al., 2016; Assmann, et al., 2015; McCall, et al., 2015; Zipris, 2010) and so is male-dominant, cell-mediated autoimmune myocarditis (Abston, et al., 2012; Pagni, et al., 2010). In addition, TLR3-TLR9 are implicated in EAE, which is also cell-mediated (Evangelista, et al., 2016). Additionally, peroxisome-proliferator activated receptor (PPAR) expression and activity in effector T cells, particularly in $A D$, is up-regulated by testosterone and down-regulated by oestrogens (Park and Choi, 2017), which is also consistent with the mechanism proposed here.

\section{ACT Provides a Mechanism for Understanding Microbiome Roles in AD}

Another aspect of AD for which current theories do not account is the changes in specific microbiome components associated with each disease. Recent research has documented AD-specific decreases in microbiome diversity in almost every AD that has been studied in this regard (e.g., Sánchez, et al., 2015; Coit and Sawalha, 2016; Scher, et al., 2016; Knip and Siljander, 2016; Vamanu, et al., 2016; Talotta, et al., 2017; Bibbò, et al., 2017). The reasons for the selective elimination of some subsets of microbes from the microbiome during the development of $A D$ are not clear (Tlaskalová-Hogenová, et al., 2004).

ACT makes very specific predictions about how AD will affect the microbiome (and vice-versa) based on a combination of complementary antigens and antigen-host mimicry. As Damian first pointed out, parasites evade immune surveillance by mimicking host antigens (Damian, 1965; Damian, 1967; 
Damian, 1989). Many commensal organisms express antigens that mimic host antigens (e.g., Coyne, et al., 2004; Szymula, et al., 2014) so that tolerance to the microbiome must be balanced with host protection against potentially pathogenic microbes (Stowell, et al., 2014; Sathyabama, et al. 2014). I suggest that the degree to which microbial components of the microbiome are tolerated by the host is, in fact, directly related to the degree to which they express host-like antigens (Root-Bernstein, 2016; Root-Bernstein, 2017).

Above I argued that the immune system has evolved to create a "body double" of the host, the array of TCR and BCR thus produced thus mimicking the overall set of host antigens. This prediction appears to be correct, as I have been able to demonstrate that every TCR that I have investigated has a high degree of similarity to at least one and usually many host proteins (Root-Bernstein, 2016; RootBernstein, 2017). It follows logically that microbial components of the host microbiome will be tolerated to the extent that they, too, mimic the TCR and BCR forming the host "body double". My own research and that of DeGroot's group verify this prediction, demonstrating a much higher degree of TCR mimicry for commensal microbes than for pathogenic ones (Root-Bernstein, 2016; Root-Bernstein, 2017; He, et al., 2015; Moise, et al., 2016).

Because of shared host-microbiome-TCR similarities, if an autoimmune disease is induced against the host, any microbiome components expressing antigens similar to those targeted by the AD will also be targeted. In consequence, each AD will target not only some set of host cells, tissues or organs, but those specific commensal microbes that share similar antigenic molecules.

There appear to be few studies that have thus far investigated the antigenic relationships between those constituents of the microbiome that are preferentially eliminated during $A D$ and whether the antigens expressed by those constituents mimic the host targets of the AD. This prediction therefore provides a good test of ACT. One notable exception is a study by Chen, et al. (2017) that demonstrated the presence of molecular mimicry in the microbiome associated with rheumatoid arthritis host antigens.

What has been investigated is the possibility that disruption of the microbiome could set the stage for, or even be the direct trigger of, particular AD. This literature is too vast to summarize here, so I will simply direct readers to the following references as a place to begin: (Dreyfus, 2017; Bogdonos and Sakkas, 2017; Tai, et al. 2016). The outstanding issue here is whether disruption of the microbiome directly leads to invasiveness of combinations of usually non-pathogenic microbiome constituents bearing high degrees of both molecular mimicry for their host and antigenic complementarity; or whether such disruption permits specific pathogen infections to take hold that are normally held in check. Either or both mechanisms could contribute to AD induction and pathogenesis and, in both cases, specific components of the microbiome would be targets of the AD.

Another logical consequence of thinking of the immune system as a "body double" for the host, and of the selection of the microbiome to mimic that "body double", is that microbiome antigens as a whole will resemble the range of TCR and BCR idiotypes displayed by the immune system. Thus, the microbiome may function as a "second immune system" (Root-Bernstein, 2016). It is well-established 
that a healthy microbiome resists pathogens and while some of this resistance is certainly due to the production of various antimicrobial molecules, it is also possible that the molecular diversity displayed by the microbiome is itself a secondary "immune system" that interacts with potential pathogens to neutralize them. This hypothesis is consistent with Davenport, et al.'s (2017) proposed mechanism for host-microbiome resistance to disease and is also consistent with observations that treatment of microbiome dysbiosis using probiotic replacement therapies can be efficacious for AD, perhaps by reinstituting tolerance to the target antigens (He, et al., 2015; de Oliveira, et al., 2017; Goyal, et al., 2018)

In light of the various connections between the adaptive, innate and microbiome systems, it is not surprising that the sex bias in $A D$ is also affected by the microbiome and vice versa. The microbiome differs in individuals by sex. Female mice colonized with male microbiomes developed significant gut inflammation and active immune responses against selected organisms over-represented in the male microbiome (Fransen, et al., 2017). Microbiome tolerance is mediated at least partly by TLR (Lai, et al., 2009; Mempel, et al., 2003) as is at least some of the sex-bias present in microbiome selection (Gomez, et al., 2015). Thus, as one would expect from a system in which AD are influenced by sex hormones and necessarily involve the microbiome, the gender bias of individual $A D$ is influenced by the microbiome and vice-versa. For example, female nonobese diabetic (NOD) mice with normal microbiomes are several times more likely to develop type 1 diabetes (T1D) than are male NOD mice with normal microbiomes. This difference disappears when female and male germ-free NOD mice are compared. A protective microbiome was supported by the presence of testosterone (Yurkovestskiy, et al., 2013). Conversely, a protective microbiome also increased testosterone production in male mice, (Markle, et al., 2013; Markle, et al., 2014). As one would expect from the ACT mechanism proposed above, microbiome-testosterone interactions are mediated through TLR (Burrows, et al., 2015; Wen, et al., 2008). Thus, there is feedback between the microbiome, TLR and sex hormones at play in AD susceptibility (Fairweather and Cihakova, 2009), and these are incorporated in ACT, but in no other current AD theory.

\section{Summary and Testable Predictions}

Antigen complementarity theory (ACT) provides a novel explanation of how microbial infections can trigger $A D$. The fundamental assumption is that $A D$ can only be triggered $b$ a pair of independent, molecularly complementary antigens. The complementarity of the antigens confuses "self"- "non-self" distinction through mimicry of the immune responses for the microbial antigens resulting in a civil war that spills over to host tissues or organs due to molecular mimicry of the microbial antigens for host antigens. $A C T$, because it requires a pair of complementary infections, explains why AD are associated with many common infections but are nonetheless themselves rare. The antigenic complementarity provides a proven mechanism for altering antigen processing and presentation and incorporates known genetic risks for $A D$ by means of this mechanism. ACT also provides a mechanism for the production of $\mathrm{CIC}$ and perivascular cuffing by reinterpreting anti-idiotype antibody and T-cell production as being the result of a pair of complementary idiotypic responses to complementary microbial antigens. ACT also provides a mechanism for synergistic stimulation of the innate immune system through complementary activation of specific sets of TLR and/or NOD. This synergistic innate mechanism is highly sensitive to further synergistic activation or deactivation by sex hormones in ways that explain sex-determined 
susceptibility to different AD. ACT further provides a mechanism for explaining how specific elements of the host microbiome are affected by, or may affect, $A D$ progression, and furthermore how sex hormones modulate the host microbiome by through synergistic actions on innate immunity. ACT explains why individual microbes are generally unable to initiate $A D$ due to their inability to break tolerance or provide continuous stimulation of innate immunity through synergistic pathways. Most importantly, ACT provides these explanations without resorting to any abnormal immune functions or chance events.

There may, of course, be other explanations for all of the phenomena integrated by ACT, but if nothing else ACT has the current advantage of bringing every major phenomenon associated with AD into a single coherent framework. The challenge for other theories of AD causation is to do the same. In the meantime, ACT can be tested further by means of a series of experimentally, clinically and epidemiologically testable predictions that, at least at present, differentiate it from all existing theories. The key testable predictions are summarized in TABLE 3. In addition to these testable predictions, ACT can also explain all known phenomena concerning the prevention or suppression of animal models of $A D$, as well as why certain approaches to microbiome manipulation can be useful as therapies for $A D$, but since these phenomena involve a vast and complicated literature, I shall leave those explanations for another paper.

It is possible that ACT is not the ultimate explanation of AD causation, but at a minimum, the data gathered here to test its explanatory power strongly suggest that any better theory will have to move away from single-agent causation (Root-Bernstein, 1989; Root-Bernstein, 1990; Root-Bernstein, 1991; Root-Bernstein, 2007; Root-Bernstein, 2009). Meanwhile, perhaps ACT is "interesting" enough to yield unexpected results that will surprise the field and open up new directions of research and therapy.

\section{TABLE 3: Experimentally and Clinically Testable Predictions}

Complementary antigens, at least one of which mimics "self", will induce AD (e.g., diphtheria + its antitoxin).

TCR and Ab hypervariable regions mimic inducing antigens and therefore identify causative agents.

$A D$ can be treated by blocking the synergistic interactions of TLR/NOD in innate immune system.

Adjuvants are not interchangeable in $A D$ induction unless they satisfy three criteria: 1 ) molecularly complementary to the antigen; 2 ) stimulate complementary innate response to antigen; 3) alter antigen processing in identical ways.

Male-dominant AD will stimulate different TLR synergies than female-dominant AD.

Microbiome alterations in each AD will be molecular mimics of the particular "self" targets and initiating infectious agents associated with that $A D$.

$A D$ can start as autoimmunity against the microbiome and spread to the host. 


\section{References}

Acharya AP, Carstens MR, Lewis JS, Dolgova N, Xia CQ, Clare-Salzler MJ, Keselowsky BG. A cell-based microarray to investigate combinatorial effects of microparticle-encapsulated adjuvants on dendritic cell activation. J Mater Chem B. 2016 Mar 7;4(9):1672-1685.

Adelman MK, Schluter SF, Robey IF, Marchalonis JJ. Natural and autoantibodies to human T-cell receptor Vbeta segments: potential roles in immunomodulation. Crit Rev Immunol. 2007;27(3):221-32.

Al-Quraishy S, Dkhil MA, Abdel-Baki AA, Araúzo-Bravo MJ, Delic D, Wunderlich F. Testosterone persistently dysregulates hepatic expression of TIr6 and TIr8 induced by Plasmodium chabaudi malaria. Parasitol Res. 2014 Oct;113(10):3609-20. doi: 10.1007/s00436-014-4026-2.

Assmann TS, Brondani Lde A, Bouças AP, Canani LH, Crispim D. Toll-like receptor 3 (TLR3) and the development of type 1 diabetes mellitus. Arch Endocrinol Metab. 2015 Feb;59(1):4-12. doi: 10.1590/2359-3997000000003.

Audibert F, Chedid L, Lefrancier P, Choay J, Lederer E. Relationship between chemical structure and adjuvant activity of some synthetic analogues of $\mathrm{N}$-acetyl-muramyl-L-alanyl-D-isoglutamine (MDP). Ann Immunol (Paris). 1977 Apr-Jun;128C(3):653-61.

Baharav E, Gur H, Fishman P, Ziporen L, Blank M, Aelion J, Kotb M, Shoenfeld Y. Superantigens and experimental SLE induced by idiotypic dysregulation. Clin Exp Rheumatol. 1996 Jul-Aug;14(4):359-66.

Barrat FJ, Coffman RL. Development of TLR inhibitors for the treatment of autoimmune diseases. Immunol Rev. 2008 Jun;223:271-83. doi: 10.1111/j.1600-065X.2008.00630.x.

Bergonzi C, Merlini GP , Morandi S, Bianchini E , Pavesi F, Bellotti V, Montecucco CM , Ascari E. Selective bone marrow involvement of lymphoplasmacytic cells secreting monoclonal IgA rheumatoid factor in a patient with Sjögren's syndrome and serum hyperviscosity. Ann. Rheum. Dis. 1987 Dec; 46(12): 938-42.

Bibbò S, Dore MP, Pes GM, Delitala G, Delitala AP. Is there a role for gut microbiota in type 1 diabetes pathogenesis? Ann Med. 2017 Feb;49(1):11-22. doi: 10.1080/07853890.2016.1222449.

Blum JS, Wearsch PA, Cresswell P. Pathways of Antigen Processing. Annu Rev Immunol. 2013; 31: 443473. doi: 10.1146/annurev-immunol-032712-095910

Bogdanos DP, Sakkas LI. From microbiome to infectome in autoimmunity. Curr Opin Rheumatol. 2017 Jul;29(4):369-373. doi: 10.1097/BOR.0000000000000394.

Bouige, P.; Iscaki, S.; Cosson, A.; Pillot , J. Molecular analysis of the modulatory factors of the response to HBsAg in mice as an approach to HBV vaccine enhancement. FEMS Immunol. Med. Microbiol. 1996, 13(1):71-9. 
Bradley RJ. Myasthenia gravis and the anti-idiotype theory of autoimmunity. Lancet. 1984 Feb 18;1(8373):396

Burrows MP, Volchkov P, Kobayashi KS, Chervonsky AV. Microbiota regulates type 1 diabetes through Toll-like receptors. Proc Natl Acad Sci U S A. 2015 Aug 11;112(32):9973-7. doi: 10.1073/pnas.1508740112. Epub 2015 Jul 27.

Chance RE, Root MA, Galloway JA. The immunogenicity of insulin preparations. Acta Endocrinol Suppl 1976; 205: 185-198.

Chen B, Sun L, Zhang X. Integration of microbiome and epigenome to decipher the pathogenesis of autoimmune diseases. J Autoimmun. 2017 Sep;83:31-42. doi: 10.1016/j.jaut.2017.03.009.

Ciháková D, Sharma RB, Fairweather D, Afanasyeva M, Rose NR. Animal models for autoimmune myocarditis and autoimmune thyroiditis. Methods Mol Med. 2004;102:175-93.

Cohen IR, Miller A, eds. 1994. Autoimmune Disease Models. A Guidebook. San Diego, etc., Academic Press.

Cohen L, Esterhazy D, Kim S-H, Lemetre C, Aguilar RR, et al. 2017. Commensal bacteria make GPCR ligands that mimic human signaling molecules. Nature 549: 48-53.

Coit $\mathrm{P}$, Sawalha $\mathrm{AH}$. The human microbiome in rheumatic autoimmune diseases: A comprehensive review. Clin Immunol. 2016 Sep;170:70-9. doi: 10.1016/j.clim.2016.07.026.

Cossart P, Sansonetti PJ. Bacterial invasion: the paradigms of enteroinvasive pathogens. Science. 2004 Apr 9;304(5668):242-8. DOI: 10.1126/science.1090124

Coyne MJ, Reinap B, Lee MM, Comstock LE. Human symbionts use a host-like pathway for surface fucosylation. Science. 2005 Mar 18;307(5716):1778-81.

Csermely P. 2006. Weak Links. The Universal Key to the Stability of Networks and Complex Systems. New York: Springer.

Cunningham MW. Post-Streptococcal Autoimmune Sequelae: Rheumatic Fever and Beyond.In: Ferretti JJ, Stevens DL, Fischetti VA, editors. Streptococcus pyogenes : Basic Biology to Clinical Manifestations [Internet]. Oklahoma City (OK): University of Oklahoma Health Sciences Center; 2016.

Cutforth T, DeMille MM, Agalliu I, Agalliu D. CNS autoimmune disease after Streptococcus pyogenes infections: animal models, cellular mechanisms and genetic factors. Future Neurol. 2016 Dec;11(1):6376.

D Ivory, D Folzenlogen. Post Streptococcal Syndromes, A Rheumatologist Perspective. The Internet Journal of Rheumatology. 2009 Volume 6 Number 2. http://ispub.com/IJRH/6/2/12159

Damian RT. Common antigens between adult Schistosoma mansoni and the laboratory mouse. J Parasitol. 1967 Feb;53(1):60-4 
Damian RT. Molecular Mimicry in Biological Adaptation. Science. 1965 Feb 19;147(3660):824.

Damian RT. Molecular mimicry: parasite evasion and host defense. Curr Top Microbiol Immunol. 1989;145:101-15.

Dasgupta S, Eudaly J. Estrogen receptor-alpha mediates Toll-like receptor-2 agonist-induced monocyte chemoattractant protein-1 production in mesangial cells. Results Immunol. 2012 Nov 10;2:196-203. doi: 10.1016/j.rinim.2012.10.002. eCollection 2012.

Davenport ER, Sanders JG, Song SJ, Amato KR, Clark AG, Knight R. The human microbiome in evolution. BMC Biol. 2017 Dec 27;15(1):127. doi: 10.1186/s12915-017-0454-7.

Davies JM. Molecular mimicry: can epitope mimicry induce autoimmune disease? Immunol Cell Biol. 1997 Apr;75(2):113-26.

De Oliveira GLV, Leite AZ, Higuchi BS, Gonzaga MI, Mariano VS. Intestinal dysbiosis and probiotic applications in autoimmune diseases. Immunology. 2017 Sep;152(1):1-12. doi: 10.1111/imm.12765.

Delgado-Vega AM, Alarcón-Riquelme ME, Kozyrev SV. Genetic associations in type I interferon related pathways with autoimmunity. Arthritis Res Ther. 2010; 12(Suppl 1): S2. Published online 2010 Apr 14. doi: $10.1186 / \operatorname{ar} 2883$

Delp, M.H.; Sutherland ,G.F.; Hashinger, E.H. Post-diphtheritic polyneuritis, a report of five cases with albuminocytologic dissociation simulating Guillain-Barré's syndrome. Ann. Intern. Med. 1946,24,618-28.

Devaraj S, Dasu MR, Rockwood J, Winter W, Griffen SC, Jialal I. Increased toll-like receptor (TLR) 2 and TLR4 expression in monocytes from patients with type 1 diabetes: further evidence of a proinflammatory state. J Clin Endocrinol Metab. 2008 Feb;93(2):578-83.

Dillon, P.F.; Root-Bernstein, R.S.; Lieder, C.M. Molecular shielding of electric field complex dissociation. Biophys. J. 2006, 90(4),1432-8

Dixit A, Tanaka A, Greer JM, Donnelly S. Novel Therapeutics for Multiple Sclerosis Designed by Parasitic Worms. Int J Mol Sci. 2017 Oct 13;18(10). pii: E2141. doi: 10.3390/ijms18102141.

Drescher KM, von Herrath M, Tracy S. Enteroviruses, hygiene and type 1 diabetes: toward a preventive vaccine. Rev Med Virol. 2015 Jan;25(1):19-32. doi: 10.1002/rmv.1815.

Dreyfus DH. Gene sharing between Epstein-Barr virus and human immune response genes. Immunol Res. 2017 Feb;65(1):37-45. doi: 10.1007/s12026-016-8814-x.

Duffy L, O'Reilly SC. Toll-like receptors in the pathogenesis of autoimmune diseases: recent and emerging translational developments. Immunotargets Ther. 2016; 5: 69-80. doi: 10.2147/ITT.S89795 
Eaton M D, Almquist S J. Autoimmunity induced by injection of virus-modified cell membrane antigens in syngeneic mice. Infect Immun. 1977 Jan; 15(1): 322-328.

Eisen, H.N.; Orris, L.; Belman, S. Elicitation of delayed allergic skin reactions with haptens; the dependence of elicitation on hapten combination with protein. J. Exp. Med. 1952, 95(5): 473-87.

Ekiert DC, Bhabha G, Elsliger M-A, Friesen RHE, Jongeneelen M, Throsby M, Goudsmit J, Wilson IA. Antibody recognition of a highly conserved influenza virus epitope: implications for universal prevention and therapy. Science. 2009 Apr 10; 324(5924): 246-251. doi: 10.1126/science.1171491

Eric D. Abston, Michael J. Coronado, Adriana Bucek, Djahida Bedja, Jaewook Shin, Joseph B. Kim, Eunyong Kim, Kathleen L. Gabrielson, Dimitrios Georgakopoulos, Wayne Mitzner, Delisa Fairweather Th2 regulation of viral myocarditis in mice: Different roles for TLR3 versus TRIF in progression to chronic disease Clinical and Developmental Immunology Volume 2012 (2012), Article ID 129486, 12 pages http://dx.doi.org/10.1155/2012/129486

Evangelista MG, Castro SB, Alves CC, Dias AT, Souza VW, Reis LB, Silva LC, Castañon MC, Farias RE, Juliano MA, Ferreira AP. Early IFN- $\gamma$ production together with decreased expression of TLR3 and TLR9 characterizes EAE development conditional on the presence of myelin. Autoimmunity. 2016 Jun;49(4):258-67. doi: 10.3109/08916934.2016.1141898.

Fairweather D, Cihakova D. Alternatively activated macrophages in infection and autoimmunity. Autoimmun. 2009 Nov-Dec;33(3-4):222-30. doi: 10.1016/j.jaut.2009.09.012.

Fairweather D, Frisancho-Kiss S, Rose NR. Sex differences in autoimmune disease from a pathological perspective. Am J Pathol. 2008 Sep;173(3):600-9. doi: 10.2353/ajpath.2008.071008.

Farzi A, Reichmann F, Meinitzer A, Raphaela Mayerhofer, Piyush Jain, Ahmed M. Hassan, Esther E. Fröhlich, Karin Wagner, Evelin Painsipp, Beate Rinner, Peter Holzer. Synergistic effects of NOD1 or NOD2 and TLR4 activation on mouse sickness behavior in relation to immune and brain activity markers. Brain, Behavior, and Immunity. 2015;44:106-120. doi:10.1016/j.bbi.2014.08.011.

Fernando MMA, Stevens CR, Walsh EC, De Jager PL, Goyette P, Plenge RM, Vyse TJ, Rioux JD. Defining the Role of the MHC in Autoimmunity: A Review and Pooled Analysis PLoS Genet. 2008 Apr; 4(4): e1000024. doi: 10.1371/journal.pgen.1000024

Finno CJ, Gianino G, Perumbakkam S, Williams ZJ, Bordbari MH, Gardner KL, Burns E, Peng S, DurwardAkhurst SA, Valberg SJ. A missense mutation in MYH1 is associated with susceptibility to immunemediated myositis in Quarter Horses. Skelet Muscle. 2018 Mar 6;8(1):7. doi: 10.1186/s13395-018-01550 .

Fischetti L, Zhong Z, Pinder CL, Tregoning JS, Shattock RJ. The synergistic effects of combining TLR ligand based adjuvants on the cytokine response are dependent upon p38/JNK signalling. Cytokine. 2017 Nov;99:287-296. doi: 10.1016/j.cyto.2017.08.009. 
Foa, P.P.; Galansino, G. Glucagon, Chemistry and Function in Health and Disease. Charles C. Thomas: Springfield, IL, 1962, pp. 6, 10, 39, 78.

Fransen F, van Beek AA, Borghuis T, Meijer B, Hugenholtz F, van der Gaast-de Jongh C, Savelkoul HF, de Jonge MI, Faas MM, Boekschoten MV, Smidt H, El Aidy S, de Vos P. The Impact of Gut Microbiota on Gender-Specific Differences in Immunity. Front Immunol. 2017 Jun 30;8:754. doi:

10.3389/fimmu.2017.00754. eCollection 2017.

Fritz, Jörg H., Girardin, Stephen E., Fitting, C., Werts, C., Mengin-Lecreulx, D., Caroff, M., Cavaillon, J.-M., Philpott, Dana J. and Adib-Conquy, M. (2005), Synergistic stimulation of human monocytes and dendritic cells by Toll-like receptor 4 and NOD1- and NOD2-activating agonists. Eur. J. Immunol., 35: 2459-2470. doi:10.1002/eji.200526286

Fujinami RS, Oldstone MB, Wroblewska Z, Frankel ME, Koprowski H. Molecular mimicry in virus infection: crossreaction of measles virus phosphoprotein or of herpes simplex virus protein with human intermediate filaments. Proc Natl Acad Sci U S A. 1983 Apr;80(8):2346-50.

Fujinami RS, Oldstone MB. Amino acid homology between the encephalitogenic site of myelin basic protein and virus: mechanism for autoimmunity. Science. 1985 Nov 29;230(4729):1043-5.

Ghosh TK, Mickelson DJ, Solberg JC, Lipson KE, Inglefield JR, Alkan SS. TLR-TLR cross talk in human PBMC resulting in synergistic and antagonistic regulation of type- 1 and 2 interferons, IL-12 and TNF-alpha. Int Immunopharmacol. 2007 Aug;7(8):1111-21.

Gomez A, Luckey D, Taneja V. The gut microbiome in autoimmunity: Sex matters. Clin Immunol. 2015 Aug;159(2):154-62. doi: 10.1016/j.clim.2015.04.016.

Gorton D, Blyth S, Gorton JG, Govan B, Ketheesan N. An alternative technique for the induction of autoimmune valvulitis in a rat model of rheumatic heart disease. J Immunol Methods. $2010 \mathrm{Apr}$ 15;355(1-2):80-5. doi: 10.1016/j.jim.2010.02.013.

Goyal A, Yeh A, Bush BR, Firek BA, Siebold LM, Rogers MB, Kufen AD, Morowitz MJ. Safety, Clinical Response, and Microbiome Findings Following Fecal Microbiota Transplant in Children With Inflammatory Bowel Disease. Inflamm Bowel Dis. 2018 Jan 18;24(2):410-421. doi: 10.1093/ibd/izx035.

Halenius A, Hengel H. Human Cytomegalovirus and Autoimmune Disease. BioMed Research International (2014), Article ID 472978, 15 pages/ http://dx.doi.org/10.1155/2014/472978

He C, Shan Y, Song W. Targeting gut microbiota as a possible therapy for diabetes. Nutr Res. 2015 May;35(5):361-7. doi: 10.1016/j.nutres.2015.03.002.

He L, De Groot AS, Bailey-Kellogg C. Hit-and-run, hit-and-stay, and commensal bacteria present different peptide content when viewed from the perspective of the T cell. Vaccine. 2015 Nov 27;33(48):6922-9. doi: 10.1016/j.vaccine.2015.08.099. 
Heeger PS, Forsthuber T, Shive C, Biekert E, Genain C, Hofstetter HH, Karulin A, Lehmann PV. Revisiting tolerance induced by autoantigen in incomplete Freund's adjuvant. J Immunol. 2000 Jun 1;164(11):577181.

Hioe, C.E.; Visciano, M.L.; Kumar, R.; Liu, J.; Mack, E.A.; Simon, R.E.; Levy, D.N.; Tuen, M. The use of immune complex vaccines to enhance antibody responses against neutralizing epitopes on HIV-1 envelope gp120. Vaccine 2009, 28(2):352-60. doi: 10.1016/j.vaccine.2009.10.040.

Hotta-Iwamura C, Tarbell KV. Type 1 diabetes genetic susceptibility and dendritic cell function: potential targets for treatment. J Leukoc Biol. 2016 Jul; 100(1): 65-80. Published online 2016 Jan 20. doi: 10.1189/jlb.3MR1115-500R

Huber A, Menconi F, Corathers S, Jacobson EM, Tomer Y. Joint Genetic Susceptibility to Type 1 Diabetes and Autoimmune Thyroiditis: from Epidemiology to Mechanisms. Endocr Rev. 2008 Oct; 29(6): 697725. Published online 2008 Sep 5. doi: 10.1210/er.2008-0015

Hunding, A., Lancet, D., Kepes, F., Minsky, A., Norris, V., Raine, D., Sriram, K., Root-Bernstein, R. "Compositional Complementarity and Prebiotic Ecosystems in the Origin of Life," Bioessays 28 (4): 399 412, 2006.

Isenberg DA, Katz D, Le Page S, Knight B, Tucker L, Maddison P, Hutchings P, Watts R, André-Schwartz J, Schwartz RS, et al. Independent analysis of the 16/6 idiotype lupus model. A role for an environmental factor? J Immunol. 1991 Dec 15;147(12):4172-7.

Isoda, R.; Robinette, R.A.; Pinder, T.L.; McArthur, W.P.; Brady, L.J. Basis of beneficial immunomodulation by monoclonal antibodies against Streptococcus mutans adhesin P1. FEMS Immunol. Med. Microbiol. 2007, 51(1):102-11.

Israelian N, Danska JS. Sex Effects at the Ramparts: Nutrient- and Microbe-Mediated Regulation of the Immune-Metabolic Interface. Adv Exp Med Biol. 2017;1043:113-140. doi: 10.1007/978-3-319-701783_7.

Itoh A, Ridgway WM. Targeting innate immunity to downmodulate adaptive immunity and reverse type 1 diabetes. Immunotargets Ther. 2017 May 19;6:31-38. doi: 10.2147/ITT.S117264.

Jackson S. Immunoglobulin-antiimmunoglobulin interactions and immune complexes in IgA nephropathy. Am. J. Kidney Dis. 1988 Nov; 12(5): 425-9.

Jamieson, S.R. Severe adult diphtheria with polyneuritis. Br. Med. J. 1947, 11,1(4488),54.

Jung YO, Cho ML, Kang CM, Jhun JY, Park JS, Oh HJ, Min JK, Park SH, Kim HY. Toll-like receptor 2 and 4 combination engagement upregulate IL-15 synergistically in human rheumatoid synovial fibroblasts. Immunol Lett. 2007 Mar 15;109(1):21-7. Epub 2007 Jan 17. 
Jung YO, Cho ML, Kang CM, Jhun JY, Park JS, Oh HJ, Min JK, Park SH, Kim HY. Toll-like receptor 2 and 4 combination engagement upregulate IL-15 synergistically in human rheumatoid synovial fibroblasts. Immunol Lett. 2007 Mar 15;109(1):21-7.

Kalia M, Jameel S. Virus entry paradigms. Amino Acids. 2011 Nov;41(5):1147-57. doi: 10.1007/s00726009-0363-3.

Kies MW, Driscoll BF, Lisak RP, Alvord EC Jr. Immunologic activity of myelin basic protein in strain 2 and strain 13 guinea pigs. J Immunol. 1975 Jul;115(1):75-9.

King AE, Horne AW, Hombach-Klonisch S., Mason JI, Critchley, HOD. Differential expression and regulation of nuclear oligomerization domain proteins NOD1 and NOD2 in human endometrium: a potential role in innate immune protection and menstruation. Molecular Human Reproduction, Vol.15, No.5 pp. 311-319, 2009. doi:10.1093/molehr/gap020

Knip M, Siljander $\mathrm{H}$. The role of the intestinal microbiota in type 1 diabetes mellitus. Nat Rev Endocrinol. 2016 Mar;12(3):154-67. doi: 10.1038/nrendo.2015.218.

Koga T, Tanaka A, Pearson CM. Synergism of immunogenic and adjuvant-active components of mycobacterial wax $D$ in the induction of adjuvant arthritis. Int Arch Allergy Appl Immunol.

1976;51(5):583-93.

Kong YC, Audibert F, Giraldo AA, Rose NR, Chedid L. Effects of natural or synthetic microbial adjuvants on induction of autoimmune thyroiditis. Infect Immun. 1985 Jul;49(1):40-5.

Kong YM, Okayasu I, Giraldo AA, Beisel KW, Sundick RS, Rose NR, David CS, Audibert F, Chedid L. Tolerance to thyroglobulin by activating suppressor mechanisms.Ann N Y Acad Sci. 1982;392:191-209.

Kosmrlj A, Jha AK, Huseby ES, Kardar M, Chakraborty AK. How the thymus designs antigen-specific and self-tolerant T cell receptor sequences. Proc Natl Acad Sci U S A. 2008 Oct 28;105(43):16671-6. doi: 10.1073/pnas.0808081105. Epub 2008 Oct 22.

Kovats S. Estrogen receptors regulate innate immune cells and signaling pathways. Cell Immunol. 2015 Apr;294(2):63-9. doi: 10.1016/j.cellimm.2015.01.018.

Krueger JM, Walter J, Karnovsky ML, Chedid L, Choay JP, Lefrancier P, Lederer E. Muramyl peptides. Variation of somnogenic activity with structure. J Exp Med. 1984 Jan 1;159(1):68-76.

Krumbiegel D, Zepp F, Meyer CU. Combined Toll-like receptor agonists synergistically increase production of inflammatory cytokines in human neonatal dendritic cells. Hum Immunol. 2007 Oct;68(10):813-22.

Kuhn, T. 1959. The Structure of Scientific Revolutions. Chicago: University of Chicago Press. 
Lai Y, Di Nardo A, Nakatsuji T, Leichtle A, Yang Y, Cogen AL, Wu ZR, Hooper LV, Schmidt RR, von Aulock S, Radek KA, Huang CM, Ryan AF, Gallo RL. Commensal bacteria regulate Toll-like receptor 3-dependent inflammation after skin injury. Nat Med. 2009 Dec;15(12):1377-82. doi: 10.1038/nm.2062.

Landsteiner, K.; van der Scheer, J. On cross reactions of immune sera to azoproteins. J. Exp. Med.. 1936, 63(3): 325-39.

Lebrun-Grandie P, Souan ML, Geffard M , Dartigues JF , Mauricet B , Orgogozo JM. Anticorps antiacétylcholine et anti-récepteur dans la myasthénie. [Anti-acetylcholine and anti-receptor antibodies in myasthenia]. Presse Med. 1987 Oct 3; 16(32): 1577-80.

Lee BR, Jeong SK, Ahn BC, Lee BJ, Shin SJ, Yum JS, Ha SJ. Combination of TLR1/2 and TLR3 ligands enhances CD4(+) T cell longevity and antibody responses by modulating type I IFN production. Sci Rep. 2016 Sep 1;6:32526. doi: 10.1038/srep32526.

Lewis M, Giraldo AA, Kong YC. Resistance to experimental autoimmune thyroiditis induced by physiologic manipulation of thyroglobulin level. Clin Immunol Immunopathol. 1987 Oct;45(1):92-104.

Li H, Zhu C, Wang B, Zhu W, Feng Y, Du F, Wang S, Hu C, Ma J, Yu X. 17ß-Estradiol Protects the Retinal Nerve Cells Suppressing TLR2 Mediated Immune-Inflammation and Apoptosis from Oxidative Stress Insult Independent of PI3K. J Mol Neurosci. 2016 Oct;60(2):195-204. doi: 10.1007/s12031-016-0794-8.

Li M, Zhou Y, Feng G, Su SB. The critical role of Toll-like receptor signaling pathways in the induction and progression of autoimmune diseases. Curr Mol Med. 2009 Apr;9(3):365-74.

Lien E, Zipris D. The role of Toll-like receptor pathways in the mechanism of type 1 diabetes. Curr Mol Med. 2009 Feb;9(1):52-68.

Liu Y, Yin H, Zhao M, Lu Q. TLR2 and TLR4 in autoimmune diseases: a comprehensive review. Clin Rev Allergy Immunol. 2014 Oct;47(2):136-47. doi: 10.1007/s12016-013-8402-y.

Mäkelä SM, Strengell M, Pietilä TE, Osterlund P, Julkunen I. Multiple signaling pathways contribute to synergistic TLR ligand-dependent cytokine gene expression in human monocyte-derived macrophages and dendritic cells. J Leukoc Biol. 2009 Apr;85(4):664-72. doi: 10.1189/jlb.0808503.

Manca,F.; Fenoglio, D.; Kunkl, A.; Cambiaggi, C.; Sasso, M.; Celada, F. Differential activation of T cell clones stimulated by macrophages exposed to antigen complexed with monoclonal antibodies. A possible influence of paratope specificity on the mode of antigen processing. J. Immunol. 1988, 140(9):2893-8.

Markle JG, Frank DN, Adeli K, von Bergen M, Danska JS. Microbiome manipulation modifies sex-specific risk for autoimmunity. Gut Microbes. 2014 Jul 1;5(4):485-93. doi: 10.4161/gmic. 29795.

Markle JG, Frank DN, Mortin-Toth S, Robertson CE, Feazel LM, Rolle-Kampczyk U, von Bergen M, McCoy KD, Macpherson AJ, Danska JS. Sex differences in the gut microbiome drive hormone-dependent regulation of autoimmunity. Science. 2013 Mar 1;339(6123):1084-8. doi: 10.1126/science.1233521 
McCall KD, Thuma JR, Courreges MC, Benencia F, James CB, Malgor R, Kantake N, Mudd W, Denlinger N, Nolan B, Wen L, Schwartz FL. Toll-like receptor 3 is critical for coxsackievirus B4-induced type 1 diabetes in female NOD mice. Endocrinology. 2015 Feb;156(2):453-61. doi: 10.1210/en.2013-2006.

McCombe PA, Greer JM, Mackay IR. Sexual dimorphism in autoimmune disease. Curr Mol Med. 2009 Dec;9(9):1058-79.

Mempel M, Voelcker V, Köllisch G, Plank C, Rad R, Gerhard M, Schnopp C, Fraunberger P, Walli AK, Ring J, Abeck D, Ollert M. Toll-like receptor expression in human keratinocytes: nuclear factor kappaB controlled gene activation by Staphylococcus aureus is toll-like receptor 2 but not toll-like receptor 4 or platelet activating factor receptor dependent. J Invest Dermatol. 2003 Dec;121(6):1389-96.

Mitchell T, Kappler J, Marrack P. Bystander virus infection prolongs activated T cell survival. J Immunol. 1999 Apr 15;162(8):4527-35.

Mohammad Hosseini A, Majidi J, Baradaran B, Yousefi M. Toll-Like Receptors in the Pathogenesis of Autoimmune Diseases. Adv Pharm Bull. 2015 Dec; 5(Suppl 1): 605-614. doi: 10.15171/apb.2015.082

Moise L, Beseme S, Tassone R, Liu R, Kibria F, Terry F, Martin W, De Groot AS. T cell epitope redundancy: cross-conservation of the TCR face between pathogens and self and its implications for vaccines and autoimmunity. Expert Rev Vaccines. 2016 May;15(5):607-17. doi: 10.1586/14760584.2016.1123098

Moreira LO, Zamboni DS. NOD1 and NOD2 Signaling in Infection and Inflammation. Frontiers in Immunology. 2012;3:328. doi:10.3389/fimmu.2012.00328.

Morgan AC Jr, Rossen RD , Twomey JJ. Naturally occurring circulating immune complexes: normal human serum contains idiotype-anti-idiotype complexes dissociable by certain IgG antiglobulins. J. Immunol. 1979 May; 122(5): 1672-80.

Morris GP, Allen PM. How the TCR balances sensitivity and specificity for the recognition of self and pathogens. Nat Immunol. 2012 Jan 19;13(2):121-8. doi: 10.1038/ni.2190.

Muller, H. [Experimental diphtheric polyneuritis]. Z ,Kinderheilkd. 1954,74(5),454-67. German.

Napolitani G, Rinaldi A, Bertoni F, Sallusto F, Lanzavecchia A. Selected Toll-like receptor agonist combinations synergistically trigger a T helper type 1-polarizing program in dendritic cells. Nat Immunol. 2005 Aug;6(8):769-76.

Ngo ST, Steyn FJ, McCombe PA. Gender differences in autoimmune disease. Front Neuroendocrinol. 2014 Aug;35(3):347-69. doi: 10.1016/j.yfrne.2014.04.004

Nordström E , Abedi-Valugerdi M , Möller E. Longevity of immune complexes and abnormal germinal centre formation in NZB mice. Scand J. Immunol. 2000 Nov; 52(5): 477-82. 
Norris V, Root-Bernstein RS. The Eukaryotic Cell Originated in the Integration and Redistribution of Hyperstructures from Communities of Prokaryotic Cells Based On Molecular Complementarity. Int. J. Mol. Sci. 2009, 10, 2611-2632; doi:10.3390/ijms10062611

Nouri-Shirazi M, Tamjidi S, Nourishirazi E, Guinet E. TLR8 combined withTLR3 or TLR4 agonists enhances DC-NK driven effector Tc1 cells. Immunol Lett. 2017 Nov 30;193:58-66. doi:

10.1016/j.imlet.2017.10.015.

Nussinovitch $U$, Shoenfeld Y. The role of gender and organ specific autoimmunity. Autoimmun Rev. 2012 May;11(6-7):A377-85. doi: 10.1016/j.autrev.2011.11.001.

Oli, M.W.; Rhodin, N.; McArthur, W.P.; Brady, L.J. Redirecting the humoral immune response against Streptococcus mutans antigen P1 with monoclonal antibodies. Infect, Immun, 2004, 72(12):6951-60.

Pagni PP, Traub S, Demaria O, Chasson L, Alexopoulou L. Contribution of TLR7 and TLR9 signaling to the susceptibility of MyD88-deficient mice to myocarditis. Autoimmunity. 2010 Jun;43(4):275-87. doi: 10.3109/08916930903509056.

Papadimitraki ED, Bertsias GK, Boumpas DT. Toll like receptors and autoimmunity: a critical appraisal. J Autoimmun. 2007 Dec;29(4):310-8.

Pappenheimer, A. M.; Jr., T. Uchida; A. A. Harper. An immunological study of the diphtheria toxin molecule. Immunochemistry 1972, 9,891-906.

Park HJ, Choi JM. Sex-specific regulation of immune responses by PPARs. Exp Mol Med. 2017 Aug 4;49(8):e364. doi: 10.1038/emm.2017.102.

Parkkola A, Laine A-P, Karhunen M, Härkönen T, Ryhänen SJ, llonen J, Knip M, the Finnish Pediatric Diabetes Register. HLA and non-HLA genes and familial predisposition to autoimmune diseases in families with a child affected by type 1 diabetes. PLoS One. 2017; 12(11): e0188402. doi:

10.1371/journal.pone.0188402

Peón AN, Ledesma-Soto Y, Olguín JE, Bautista-Donis M, Sciutto E, Terrazas LI. Helminth Products Potently Modulate Experimental Autoimmune Encephalomyelitis by Downregulating Neuroinflammation and Promoting a Suppressive Microenvironment. Mediators Inflamm. 2017;2017:8494572. doi: 10.1155/2017/8494572.

Pisetsky DS. Autoimmunity: the nuclear arsenal of autoimmunity. Immunol Cell Biol. 2007; 85, 344-345.

Pizarro-Cerdá J, Cossart P. 2006. Bacterial Adhesion and Entry into Host Cells Cell. 124(4) 715-727. doi.org/10.1016/j.cell.2006.02.012

Plotz PH. Autoantibodies are anti-idiotype antibodies to antiviral antibodies. Lancet. 1983 Oct 8;2(8354):824-6. 
Randall, R. E. ; Young, D. F. Humoral and cytotoxic T cell immune responses to internal and external structural proteins of simian virus 5 induced by immunization with solid matrix antibody- antigen complexes. J. Gen. Virology 1988, 69: 25052516.

Re F, Strominger JL. IL-10 released by concomitant TLR2 stimulation blocks the induction of a subset of Th1 cytokines that are specifically induced by TLR4 or TLR3 in human dendritic cells. J Immunol. 2004 Dec 15;173(12):7548-55.

Rhoads, P.S. Commercial preparations of diphtheria toxin-antitoxin. JAMA 1928, 90(4), 254-257.

Ribeta D, Cossart, P. 2015. How bacterial pathogens colonize their hosts and invade deeper tissues. Microbes and Infection, 17 (3) 173-183.

Robinet M, Maillard S, Cron MA, Berrih-Aknin S, Le Panse R. Review on Toll-Like Receptor Activation in Myasthenia Gravis: Application to the Development of New Experimental Models. Clin Rev Allergy Immunol. 2017 Feb;52(1):133-147. doi: 10.1007/s12016-016-8549-4.

Root Bernstein, R. S. and Dillon, P. F. "Molecular Complementarity, I: The Molecular Complementarity Theory of the Origin and Evolution of Life." Journal of Theoretical Biology, 188: 447 479, 1997.

Root-Bernstein R, Fairweather D. Complexities in the relationship between infection and autoimmunity. Curr Allergy Asthma Rep. 2014 Jan;14(1):407. doi: 10.1007/s11882-013-0407-3.

Root-Bernstein R, Fairweather D. Unresolved issues in theories of autoimmune disease using myocarditis as a framework. J Theor Biol. 2015 Jun 21;375:101-23. doi: 10.1016/j.jtbi.2014.11.022.

Root-Bernstein R. A modular hierarchy-based theory of the chemical origins of life based on molecular complementarity Acc. Chem. Res., 2012. 45 (12): 2169-2177, 2012. DOI: 10.1021/ar200209k; http://pubs.acs.org/toc/achre4/45/12

Root-Bernstein R. A measles-derived peptide treats and vaccinates against adjuvant arthritis. Autoimmun Rev. 2009 Mar;8(5):405-9. doi: 10.1016/j.autrev.2006.03.013.

Root-Bernstein R. Autoimmunity and the microbiome: T-cell receptor mimicry of "self" and microbial antigens mediates self tolerance in holobionts: The concepts of "holoimmunity" (TcR-mediated tolerance for the holobiont) and "holoautoimmunity" (loss of tolerance for the holobiont) are introduced. Bioessays. 2016 Nov;38(11):1068-1083. doi: 10.1002/bies.201600083.

Root-Bernstein R. How to Make a Non-Antigenic Protein (Auto) Antigenic: Molecular Complementarity Alters Antigen Processing and Activates Adaptive-Innate Immunity Synergy.Anticancer Agents Med Chem. 2015;15(10):1242-59.

Root-Bernstein R. Human Immunodeficiency Virus Proteins Mimic Human T Cell Receptors Inducing Cross-Reactive Antibodies. Int J Mol Sci. 2017 Oct 3;18(10). pii: E2091. doi: 10.3390/ijms18102091. 
Root-Bernstein RS, Podufaly A. Autoreactive T-cell receptor (Vbeta/D/Jbeta) sequences in diabetes recognize insulin, the insulin receptor, and each other, and are targets of insulin antibodies. The Open Autoimmunity Journal. 4: 10-22, 2012. DOI: 10.2174/1876894601204010010

Root-Bernstein RS, Westall FC. Sleep factors: do muramyl peptides activate serotonin binding sites? Lancet. 1983 Mar 19;1(8325):653.

Root-Bernstein RS, Westall FC. Serotonin binding sites. II. Muramyl dipeptide binds to serotonin binding sites on myelin basic protein, LHRH, and MSH-ACTH 4-10. Brain Res Bull. 1990 Dec;25(6):827-41.

Root-Bernstein RS. Antigenic complementarity in the induction of autoimmunity: a general theory and review. Autoimmun. Rev. 2007 Apr; 6(5): 272-7.

Root Bernstein RS. Multiple antigen mediated autoimmunity (MAMA) in AIDS: A possible model for post infectious autoimmunity. Res. Immunol. 1990; 141: 321-339.

Root-Bernstein RS. Rethinking AIDS. 1989; New York: Free Press.

Root Bernstein RS. Self, nonself, and the paradoxes of autoimmunity. In Tauber Al, editor. Organism and the Development of Self 1991; Boston: Kluwer, pp. 159209.

Root-Bernstein RS. The Role of Antigenic Complementarity in the Induction of Autoimmunity. In: Columbus, F., Ed., Autoimmunity: Role, Regulation and Disorders. Nova Press (2009).

Root-Bernstein, R. 1989. Discovering: Inventing and Solving Problems at the Frontiers of Science. Cambridge MA: Harvard University Press.

Root-Bernstein, R.S.; Dobbelstein, C. Insulin binds to glucagon forming a complex that is hyper-antigenic and inducing complementary antibodies having an idiotype-antiidiotype relationship. Autoimmunity. 2001, 33(3),153-69.

Rose LM , Goldman M , Lambert PH. The production of anti-idiotypic antibodies and of idiotype-antiidiotype immune complexes after polyclonal activation induced by bacterial LPS. J. Immunol. 1982 May; 128(5): 2126-33.

Rose NR, Bona C. Defining criteria for autoimmune diseases (Witebsky's postulates revisited). Immunol Today. 1993 Sep;14(9):426-30.

Rose NR. Autoimmunity in coxsackievirus infection. Curr Top Microbiol Immunol. 2008;323:293-314.

Rose NR. Negative selection, epitope mimicry and autoimmunity. Curr Opin Immunol. 2017 Dec;49:5155. doi: 10.1016/j.coi.2017.08.014.

Rosenshine I, Finlay BB. Exploitation of host signal transduction pathways and cytoskeletal functions by invasive bacteria. Bioessays. 1993 Jan;15(1):17-24. 
Rubtsova K, Marrack P, Rubtsov AV. Sexual dimorphism in autoimmunity. J Clin Invest. 2015 Jun;125(6):2187-93. doi: 10.1172/JCI78082.

S Lashkari B, Anumba DO. Estradiol alters the immune-responsiveness of cervical epithelial cells stimulated with ligands of Toll-like receptors 2 and 4. PLoS One. 2017 Mar 15;12(3):e0173646. doi: 10.1371/journal.pone.0173646.

Sakata S, Shima H, Komaki T, Kojima N, Nakamura S, Miura K, Tarutani O. [Investigations on the mechanism(s) of the production of anti-thyroid hormone antibodies 4: the effect of adjuvant on the immune response to human thyroglobulin]. Nihon Naibunpi Gakkai Zasshi. 1985 Aug 20;61(8):794-801. [Article in Japanese]

Salk J, Romine JS, Westall FC, Wiederholt WC. Myelin basic protein studies in experimental allergic encephalomyelitis and multiple sclerosis: a summary with theoretical considerations of multiple sclerosis etiology. In: Experimental Allergic Encephalomyelitis and Multiple Sclerosis, AN Davison and ML Cuzner, eds. London: Academic Press, 1980, pp. 141-156.

Sánchez B, Hevia A, González S, Margolles A. Interaction of Intestinal Microorganisms with the Human Host in the Framework of Autoimmune Diseases. Front Immunol. 2015 Nov 20;6:594. doi: 10.3389/fimmu.2015.00594. eCollection 2015.

Sathyabama S, Khan N, Agrewala JN. Friendly pathogens: prevent or provoke autoimmunity. Crit Rev Microbiol. 2014 Aug;40(3):273-80. doi: 10.3109/1040841X.2013.787043.

Sato S, Nomura F, Kawai T, Takeuchi O, Mühlradt PF, Takeda K, Akira S. Synergy and cross-tolerance between toll-like receptor (TLR) 2- and TLR4-mediated signaling pathways. J Immunol. 2000 Dec 15;165(12):7096-101.

Scher JU, Joshua V, Artacho A, Abdollahi-Roodsaz S, Öckinger J, Kullberg S, Sköld M, Eklund A, Grunewald J, Clemente JC, Ubeda C, Segal LN, Catrina AI. The lung microbiota in early rheumatoid arthritis and autoimmunity. Microbiome. 2016 Nov 17;4(1):60.

Serreze DV, Ottendorfer EW, Ellis TM, Gauntt CJ, Atkinson MA. Acceleration of type 1 diabetes by a coxsackievirus infection requires a preexisting critical mass of autoreactive T-cells in pancreatic islets. Diabetes. 2000 May;49(5):708-11.

Shigemoto K. Myasthenia gravis induced by autoantibodies against MuSK Acta Myol. 2007 Dec; 26(3): 185-191.

Simpson IJ , Myles MJ , Smith GW. Immune complexes in normal subjects. J. Clin. Lab. Immunol. 1983 Jul; 11(3): 119-22.

Stowell SR1, Arthur CM1, McBride R2, Berger O3, Razi N3, Heimburg-Molinaro J4, Rodrigues LC4, Gourdine JP4, Noll AJ4, von Gunten S5, Smith DF4, Knirel YA6, Paulson JC3, Cummings RD4. Microbial 
glycan microarrays define key features of host-microbial interactions. Nat Chem Biol. 2014 Jun;10(6):470-6. doi: 10.1038/nchembio.1525.

Strongwater SL, Dorovini-Zis K, Ball RD, Schnitzer TJ. A murine model of polymyositis induced by coxsackievirus B1 (Tucson strain). Arthritis Rheum. 1984 Apr;27(4):433-42.

Svenson J, Cunningham M, Dasgupta S, Gilkeson GS. Estrogen receptor alpha modulates mesangial cell responses to toll-like receptor ligands. Am J Med Sci. 2014 Dec;348(6):492-500. doi:

10.1097/MAJ.0000000000000339.

Szymula A, Rosenthal J, Szczerba BM, Bagavant H, Fu SM, Deshmukh US. T cell epitope mimicry between Sjögren's syndrome Antigen A (SSA)/Ro60 and oral, gut, skin and vaginal bacteria. Clin Immunol. 2014 May-Jun;152(1-2):1-9. doi: 10.1016/j.clim.2014.02.004.

Tada H, Aiba S, Shibata K, Ohteki T, Takada H. Synergistic effect of NOD1 and NOD2 agonists with tolllike receptor agonists on human dendritic cells to generate interleukin-12 and Thelper type 1 cells. Infect Immun. 2005 Dec;73(12):7967-76.

Tai N, Peng J, Liu F, Gulden E, Hu Y, Zhang X, Chen L, Wong FS, Wen L. Microbial antigen mimics activate diabetogenic CD8 T cells in NOD mice. J Exp Med. 2016 Sep 19;213(10):2129-46. doi:

10.1084/jem.20160526. Epub 2016 Sep 12.

Tai N, Wong FS, Wen L. The role of the innate immune system in destruction of pancreatic beta cells in NOD mice and humans with type I diabetes. J Autoimmun. $2016 \mathrm{Jul} ; 71: 26-34$. doi:

10.1016/j.jaut.2016.03.006.

Tai N, Wong FS, Wen L. The role of the innate immune system in destruction of pancreatic beta cells in NOD mice and humans with type I diabetes. J Autoimmun. $2016 \mathrm{Jul} ; 71: 26-34$. doi:

10.1016/j.jaut.2016.03.006.

Takada H, Uehara A. Enhancement of TLR-mediated innate immune responses by peptidoglycans through NOD signaling. Curr Pharm Des. 2006;12(32):4163-72.

Takeuchi Y, Root-Bernstein RS, Shih JC. Peptide displacement of [3H]5-hydroxytryptamine binding to bovine cortical membranes. Brain Res Bull. 1990 Dec;25(6):817-20.

Talotta R, Atzeni F, Ditto MC, Gerardi MC, Sarzi-Puttini P. The Microbiome in Connective Tissue Diseases and Vasculitides: An Updated Narrative Review. J Immunol Res. 2017;2017:6836498. doi:

10.1155/2017/6836498.

Thorley JA, McKeating JA, Rappoport JZ. Mechanisms of viral entry: sneaking in the front door.

Protoplasma. 2010 Aug; 244(1-4): 15-24. doi: 10.1007/s00709-010-0152-6

Tian J, Avalos AM, Mao S-Y, Chen B, Senthil K, Wu H. Toll-like receptor 9-dependent activation by DNAcontaining immune complexes is mediated by HMGB1 and RAGE. Nat. Immunol. 2007; 8: 487-496. 
Tincani A, Rebaioli CB , Taglietti M , Shoenfeld Y. Heart involvement in systemic lupus erythematosus, anti-phospholipid syndrome and neonatal lupus. Rheumatology (Oxford) 2006 Oct; 45 Suppl 4: iv8-13. Tlaskalová-Hogenová H, Stepánková R, Hudcovic T, Tucková L, Cukrowska B, Lodinová-Zádníková R, Kozáková H, Rossmann P, Bártová J, Sokol D, Funda DP, Borovská D, Reháková Z, Sinkora J, Hofman J, Drastich $\mathrm{P}$, Kokesová A. Commensal bacteria (normal microflora), mucosal immunity and chronic inflammatory and autoimmune diseases. Immunol Lett. 2004 May 15;93(2-3):97-108.

Tochimoto A, Kawaguchi Y, Yamanaka H. Genetic Susceptibility to Interstitial Lung Disease Associated with Systemic Sclerosis. Clin Med Insights Circ Respir Pulm Med. 2015; 9(Suppl 1): 135-140. doi: 10.4137/CCRPM.S23312

Tomer Y. Genetic Susceptibility to Autoimmune Thyroid Disease: Past, Present, and Future. Thyroid. 2010 Jul; 20(7): 715-725. doi: 10.1089/thy.2010.1644

Törmäkangas L,Erkkilä L,Korhonen T, Tiirola T, Bloigu A, Saikku P, Leinonen M. Effects of Repeated Chlamydia pneumoniae Inoculations on Aortic Lipid Accumulation and Inflammatory Response in C57BL/6J Mice. Infect Immun. 2005 Oct; 73(10): 6458-6466. doi: 10.1128/IAI.73.10.6458-6466.2005

Triantafyllopoulou A, Tapinos N, Moutsopoulos HM. Evidence for coxsackievirus infection in primary Sjögren's syndrome. Arthritis Rheum. 2004 Sep;50(9):2897-902.

Tsuji Y, Watanabe T, Kudo M, Arai H, Strober W, Chiba T. Sensing of commensal organisms by the intracellular sensor NOD1 mediates experimental pancreatitis. Immunity. 2012 Aug 24;37(2):326-38. doi: 10.1016/j.immuni.2012.05.024.

Tzioufas AG, Routsias JG. Idiotype, anti-idiotype network of autoantibodies: pathogenetic considerations and clinical application. Autoimmun Rev. 2010 Jul;9(9):631-3. doi: 10.1016/j.autrev.2010.05.013.

Vamanu E, Pelinescu D, Sarbu I. Comparative Fingerprinting of the Human Microbiota in Diabetes and Cardiovascular Disease. J Med Food. 2016 Dec;19(12):1188-1195.

Vandenbark AA, Hashim G, Offner H. Immunization with a synthetic T-cell receptor V-region peptide protects against experimental autoimmune encephalomyelitis. Nature. 1989 Oct 12;341(6242):541-4.

Vanhoutte F, Paget C, Breuilh L, Fontaine J, Vendeville C, Goriely S, Ryffel B, Faveeuw C, Trottein F. Tolllike receptor (TLR)2 and TLR3 synergy and cross-inhibition in murine myeloid dendritic cells. Immunol Lett. 2008 Feb 15;116(1):86-94. doi: 10.1016/j.imlet.2007.11.014.

von Herrath MG, Fujinami RS, Whitton JL. Microorganisms and autoimmunity: making the barren field fertile? Nat Rev Microbiol. 2003 Nov;1(2):151-7.

Vyas JM, Van der Veen, AG, Ploegh HL. The known unknowns of antigen processing and presentation Nature Reviews Immunol. 2008; 8: 607-618. doi:10.1038/nri2368 
Waksman, B,H.; Adams, R.D.; Mansmann, H.C., Jr. Experimental study of diphtheritic polyneuritis in the rabbit and guinea pig. I. Immunologic and histopathologic observations. J. Exp. Med. 1957,105(6),591614.

Waldner $\mathrm{H}$. The role of innate immune responses in autoimmune disease development. Autoimmun Rev. 2009 Mar;8(5):400-4. doi: 10.1016/j.autrev.2008.12.019.

Walker LM, Phogat SK, Chan-Hui P-Y, et al. Broad and Potent Neutralizing Antibodies from an African Donor Reveal a New HIV-1 Vaccine Target. Science (New York, N.y). 2009;326(5950):285-289. doi:10.1126/science.1178746.

Wang SH, Bretz JD, Phelps E, Mezosi E, Arscott PL, Utsugi S, Baker JR Jr. A unique combination of inflammatory cytokines enhances apoptosis of thyroid follicular cells and transforms nondestructive to destructive thyroiditis in experimental autoimmune thyroiditis. J Immunol. 2002 Mar 1;168(5):2470-4.

Weigle WO. Analysis of autoimmunity through experimental models of thyroiditis and allergic encephalomyelitis. Adv Immunol. 1980;30:159-273

Weigle WO. Analysis of autoimmunity through experimental models of thyroiditis and allergic encephalomyelitis. Adv Immun 1980; 30:159-273.

Wen L, Ley RE, Volchkov PY, Stranges PB, Avanesyan L, Stonebraker AC, Hu C, Wong FS, Szot GL, Bluestone JA, Gordon JI, Chervonsky AV. Innate immunity and intestinal microbiota in the development of Type 1 diabetes. Nature. 2008 Oct 23;455(7216):1109-13. doi: 10.1038/nature07336.

Wikén M, Grunewald J, Eklund A, Wahlström J. Higher monocyte expression of TLR2 and TLR4, and enhanced pro-inflammatory synergy of TLR2 with NOD2 stimulation in sarcoidosis. J Clin Immunol. 2009 Jan;29(1):78-89. doi: 10.1007/s10875-008-9225-0.

Williams WV, Kyriakos M, Sharp GC, Braley-Mullen H. Effects of the adjuvants SGP and Quil A on the induction of experimental autoimmune thyroiditis in mice. Cell Immunol. 1987 Feb;104(2):296-303.

Witebsky E, Rose NR, Terplan K, Paine JR, Egan RW. Chronic thyroiditis and autoimmunization. J Am Med Assoc. $1957 \mathrm{Jul}$ 27;164(13):1439-47.

Yarwood A, Huizinga TWZ, Worthington J. The genetics of rheumatoid arthritis: risk and protection in different stages of the evolution of RA. Rheumatology (Oxford) 2016 Feb; 55(2): 199-209.

Young NA, Valiente GR, Hampton JM, Wu LC, Burd CJ, Willis WL, Bruss M, Steigelman H, Gotsatsenko M, Amici SA, Severin M, Claverie LM, Guerau-de-Arellano M, Lovett-Racke A, Ardoin S, Jarjour WN.

Estrogen-regulated STAT1 activation promotes TLR8 expression to facilitate signaling via microRNA-21 in systemic lupus erythematosus. Clin Immunol. 2017 Mar;176:12-22. doi: 10.1016/j.clim.2016.12.005.

Young NA, Wu LC, Burd CJ, Friedman AK, Kaffenberger BH, Rajaram MV, Schlesinger LS, James H, Shupnik MA, Jarjour WN. Estrogen modulation of endosome-associated toll-like receptor 8: an IFNa- 
39

independent mechanism of sex-bias in systemic lupus erythematosus. Clin Immunol. 2014 Mar;151(1):66-77. doi: 10.1016/j.clim.2014.01.006.

Yurkovetskiy L, Burrows M, Khan AA, Graham L, Volchkov P, Becker L, Antonopoulos D, Umesaki Y, Chervonsky AV. Gender bias in autoimmunity is influenced by microbiota. Immunity. 2013 Aug 22;39(2):400-12. doi: 10.1016/j.immuni.2013.08.013.

Zagoriti Z, Kambouris ME, Patrinos GP, Tzartos SJ, Poulas K. Recent Advances in Genetic Predisposition of Myasthenia Gravis Biomed Res Int. 2013; 2013: 404053. doi: 10.1155/2013/404053

Zanetti M. Anti-idiotypic antibodies and autoantibodies. Ann N Y Acad Sci. 1983;418:363-78.

Zipris D. Toll-like receptors and type 1 diabetes. Adv Exp Med Biol. 2010;654:585-610. doi: 10.1007/97890-481-3271-3_25. 